Florida International University FIU Digital Commons

\title{
An Examination of Lotka's law in the Field of Library and Information Studies
}

Consuella Antoinette Askew

Florida International University

DOI: $10.25148 /$ etd.FI10022502

Follow this and additional works at: https://digitalcommons.fiu.edu/etd

\section{Recommended Citation}

Askew, Consuella Antoinette, "An Examination of Lotka's law in the Field of Library and Information Studies" (2008). FIU Electronic Theses and Dissertations. 182.

https://digitalcommons.fiu.edu/etd/182

This work is brought to you for free and open access by the University Graduate School at FIU Digital Commons. It has been accepted for inclusion in FIU Electronic Theses and Dissertations by an authorized administrator of FIU Digital Commons. For more information, please contact dcc@fiu.edu. 


\title{
FLORIDA INTERNATIONAL UNIVERSITY
}

Miami, Florida

\section{AN EXAMINATION OF LOTKA'S LAW IN THE FIELD OF LIBRARY AND INFORMATION STUDIES}

\author{
A dissertation submitted in partial fulfillment of the \\ requirements for the degree of \\ DOCTOR OF EDUCATION \\ in \\ HIGHER EDUCATION \\ by \\ Consuella A. Askew \\ 2008
}


To: Dean Luis Mirón

College of Education

This dissertation, written by Consuella A. Askew, and entitled An Examination of Lotka's law in the Field of Library and Information Studies, having been approved in respect to style and intellectual content, is referred to you for judgment.

We have read this dissertation and recommend that it be approved.

Leonard Bliss

Janice Sandiford

Joan Wynne

Kingsley Banya, Major Professor

Date of Defense: March 31, 2008

The dissertation of Consuella A. Askew is approved.

Dean Luis Mirón

College of Education

Dean George Walker

University Graduate School

Florida International University, 2008 
(C) Copyright 2008 by Consuella A. Askew

All rights reserved. 


\section{DEDICATION}

This dissertation is dedicated to my mother who has been my lead cheerleader

throughout this effort, to my husband and son (who have eaten take-out more often than not during the past six months) and to the rest of my family for their unflagging encouragement and support. 


\section{ACKNOWLEDGMENTS}

I am deeply appreciative and grateful for the unflagging support of my committee members, this dissertation would not have been written if not for them. Although I drew considerable knowledge from the group, each member also added a something special to my experience: Dr. Banya's periodic KITAs helped me keep my eyes on the prize; Dr. Sandiford's careful review of each offering insightful comments and suggestions helped keep me on track with my writing; Dr. Bliss' patience and understanding when it came to using my rusty statistics skills and knowledge; and Dr. Wynne for agreeing to serve on my committee and continuing to serve even when my topic changed at least three times. I would also like to thank Dr. Teresa Y. Neely and Dr. Pauletta Bracey for their feedback and input along the way. 


\section{ABSTRACT OF THE DISSERTATION \\ AN EXAMINATION OF LOTKA'S LAW IN THE FIELD OF \\ LIBRARY AND INFORMATION STUDIES}

by

Consuella A. Askew

Florida International University, 2008

Miami, Florida

Professor Kingsley Banya, Major Professor

The purpose of this study was to test Lotka's law of scientific publication productivity using the methodology outlined by Pao (1985), in the field of Library and Information Studies (LIS). Lotka's law has been sporadically tested in the field over the past $30+$ years, but the results of these studies are inconclusive due to the varying methods employed by the researchers.

A data set of 1,856 citations that were found using the ISI Web of Knowledge databases were studied. The values of $n$ and $c$ were calculated to be 2.1 and 0.6418 $(64.18 \%)$ respectively. The Kolmogorov-Smirnov (K-S) one sample goodness-of-fit test was conducted at the 0.10 level of significance. The $D_{\max }$ value is 0.022758 and the calculated critical value is 0.026562 . It was determined that the null hypothesis stating that there is no difference in the observed distribution of publications and the distribution obtained using Lotka's and Pao's procedure could not be rejected.

This study finds that literature in the field of library and Information Studies does conform to Lotka's law with reliable results. As result, Lotka's law can be used in LIS as 
a standardized means of measuring author publication productivity which will lead to findings that are comparable on many levels (e.g., department, institution, national). Lotka's law can be employed as an empirically proven analytical tool to establish publication productivity benchmarks for faculty and faculty librarians. Recommendations for further study include (a) exploring the characteristics of the high and low producers; (b) finding a way to successfully account for collaborative contributions in the formula; and, (c) a detailed study of institutional policies concerning publication productivity and its impact on the appointment, tenure and promotion process of academic librarians. 


\section{TABLE OF CONTENTS}

CHAPTER

PAGE

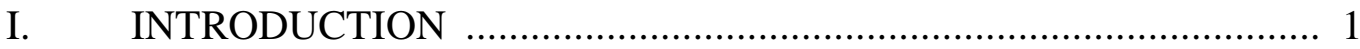

Purpose of the Study ................................................................ 2

Research Questions .............................................................. 3

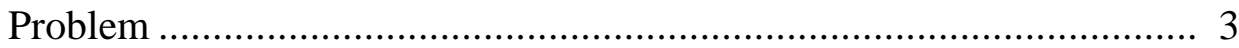

Background of the Study .............................................................. 5

Theoretical Framework ................................................................ 6

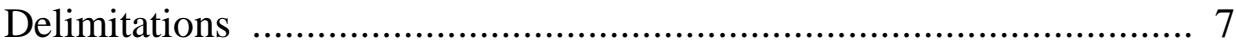

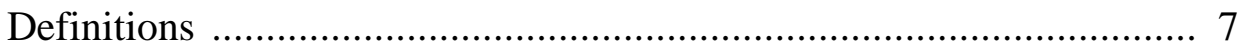

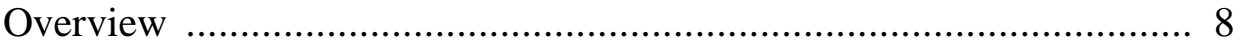

II. REVIEW OF RELATED LITERATURE _.................................. 9

Lotka's Law ............................................................................ 9

Application of Lotka's Law in Library and Information Studies .......... 12

Application of Lotka's Law in Other Disciplines ............................. 19

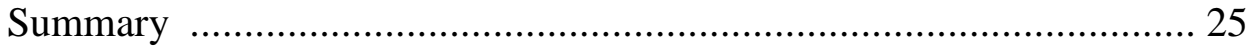

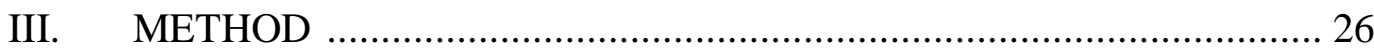

Design ................................................................................ 26

Procedure and Data Analysis ........................................................... 27

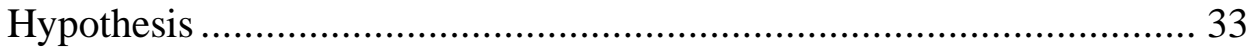

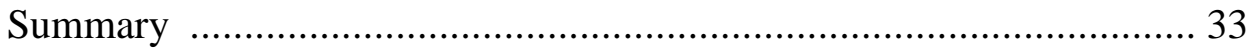

IV. ANALYSIS AND RESULTS _.................................................... 35

Data Analysis for Research Questions ........................................ 35

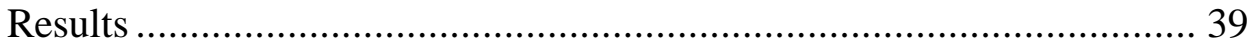

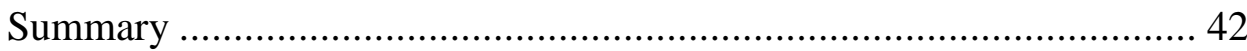

V. CONCLUSIONS AND RECOMMENDATIONS ........................... 44

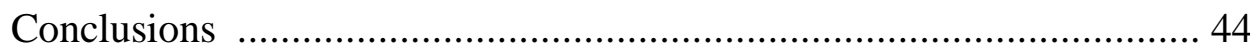

Recommendations ..................................................................... 48

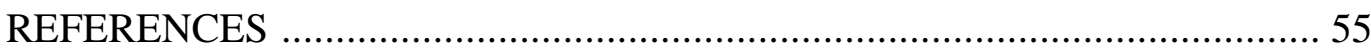

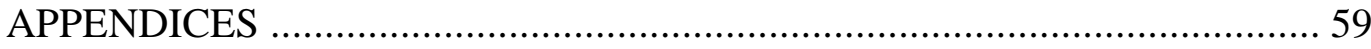

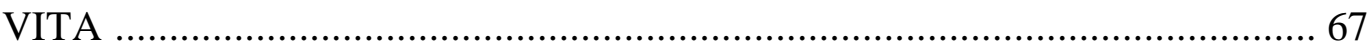




\section{LIST OF TABLES}

TABLE

PAGE

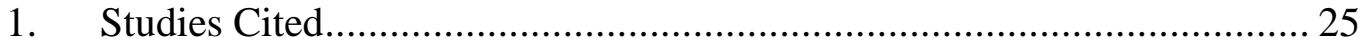

2. Library and Information Studies Journal

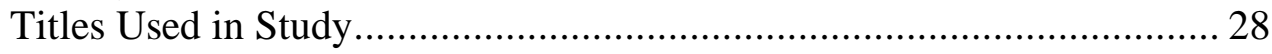

3. Calculation of $n$ for the First 18 Points Using

Pao's Suggested Table .......................................................................... 36

4. K-S Test of Observed and Expected

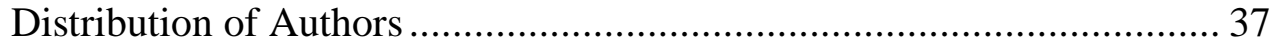

5. The Top Five Most Productive Authors ................................................ 39 


\section{CHAPTER I}

\section{INTRODUCTION}

Infometrics is defined by Egghe (2005) as "the science dealing with the quantitative aspects of information" (p. 7). This is a broad expression of a concept that also includes bibliometrics, the application of mathematical and statistical methods to books and other communication medium (Pritchard, 1969). One area of bibliometric studies frequently used by librarians is citation analysis, which is used to for the purposes of collection development, acquisitions, and the tenure and promotion process (Budd, 1999; Budd \& Seavey, 1990; Gross \& Gross, 1927; Krausse \& Sieburth, 1985; Parks \& Riggs, 1991; Weller, Wiberley \& Hurd, 1999). Citation analysis has been employed by the library profession throughout its existence and over the past two decades this type of study has steadily increased to look at the publication patterns of academic librarians and library school faculty from every perspective. These studies have explored the impact of gender, geographic location, library type and faculty status on the publication productivity of librarians and library school faculty, etc. (Budd \& Seavy, 1990; Hart, 2000; Joswick, 1999; Nisonger \& Davis, 2005; Watson, 1985; Wiberley, Jr., Hurd, \& Weller, 2006).

While bibliometric studies have been around for decades in librarianship (since 1926), the use of bibliometrics to study author publication productivity has only gained foothold in the field since the early 1970's. Meanwhile researchers in the scientific fields have been using bibliometrics to study the productivity of its scholars since the early part of the $20^{\text {th }}$ century, starting with Alfred J. Lotka's 1926 seminal study on publication productivity of chemists and physicists. 
The results of Lotka's study indicated that in the scientific field, 60 percent of authors make a single contribution during a given time period and as the number of contributions by a single author increases, the number of authors decreases. Lotka's formula for this inverse power law of publication productivity is expressed in general terms as $x^{n} y=$ constant. Where the number of authors, $y_{x}$, each credited with $\mathrm{x}$ number of papers, is inversely proportional to $\mathrm{x}$, which is the output of each individual author (Lotka, 1926, p. 320). In a 1985 article, Pao, explains Lotka's law in more specific terms as follows:

...the number of authors, $y_{x}$, each credited with $x$ number of papers, is inversely proportional to $x$, which is the output of each individual author. The relation is expressed as $x^{n} * y_{x}=c$ where $y_{x}$ is the number of authors making $x$ contributions to the subject, and $n$ and $c$ are the two constants to be estimated for the specific set of data. (p. 305)

Referred to as Lotka's law of author publication productivity this formula has been employed in various disciplines to predict publication productivity.

$$
\text { Purpose of the Study }
$$

The purpose of this study was to test Lotka's law of scientific publication productivity, in the field of Library and Information Studies (LIS), to ascertain if it can be used as an analytical technique that can help university and library administrators set appropriate and statistically supported benchmark requirements for faculty publication productivity. Lotka's law has been tested in various fields and disciplines over the past 30 years but the results are questionable due to the varying methods employed by the researchers.

Pao asserts that while a number of studies have been undertaken to investigate Lotka's law many have not adhered to his methodology. Instead variations of his original 
method e.g., counting co-authors instead of lead authors and the use of small sample sizes have been employed to achieve the same value for his coefficient $n$ (the calculated slope of the data), which was $2.021 \pm 1.888$ and $1.888 \pm 0.007$ respectively for each data set studied. In other cases, because the slope of the data was close to 2.0 many studies automatically and erroneously use $n=2$ for their calculations of $C$. A review of the LIS research literature concerning publication productivity revealed that many of the samples differ significantly in size and breadth of source than those in Lotka's study.

As a result of such observations concerning studies of Lotka's law in LIS and other fields, Pao suggests that studies testing the appropriateness of Lotka's formula should be conducted adhering closely to Lotka's methodology in order to achieve valid results. The results of this study will provide empirical evidence as to the applicability of Lotka's inverse power law to publication productivity in the field of LIS specifically library and information studies. It will also serve to establish a baseline of trend data that future studies can build upon.

\section{Research Questions}

The following research questions were used to focus this study:

Question \#1: To what extent can Lotka's law be used to predict publication productivity in the field of library and Information Studies?

Question \#2: What are the characteristics of the high producing LIS authors based on the data available?

\section{Problem}

Although author publication productivity has been studied off and on since the early 1970s, renewed interest in the topic has spurred a number of studies since the 1990s on the publication trends of academic librarians and library and information studies 
faculty. This interest in publication productivity is mostly likely fueled by the publication requirements placed on library faculty working in academic libraries and library schools in order for them to achieve and maintain faculty status within their institutions. For the most part, these studies of publication trends were meant to unearth best practices at institutions with higher publication productivity and to inspire further study of factors impacting publication efforts. The shortcomings of these studies in librarianship are that the methodologies employed by the researchers vary from study to study are not conjoined by a common set of theories or a theoretical framework. Instead, each new study introduced in the literature employs a new methodology meant to improve upon the existing study or studies on the same topic. This lack of a theoretical underpinning leaves the profession bereft of empirically sound baseline data from which to draw conclusions that are widely applicable.

Lotka's law has been tested and used to determine publication productivity in a number of fields and subject areas, including LIS. However, few of these studies have followed Lotka's methodology closely leading to unreliable results at best. Pao (1985) and Coile (1977) state that the results of such studies are questionable due to the varying methodologies used. Pao (1985) suggests that Lotka's law is based "on the conformity of one experiment, [and that] standardized testing procedures be performed on other data sets" (p. 307). This study will follow her suggestion and test Lotka's law of publication productivity, in the field of LIS.

The results of this study may have implications for higher education policies concerning the publication productivity as it pertains to performance evaluation for academic librarians in faculty lines at higher education institutions and collegiate faculty 
at large seeking initial appointment, tenure, or promotion. Additional data can be teased from this study to identify best practices in the field that would promote publication productivity by identifying institutions with high author publication productivity and studying the internal processes or support that contribute to this trend.

Background of the Study

There have been a number of studies conducted over the last decade or so that have looked at the publication trends of librarians. These studies have mainly concentrated on academic librarians and library school faculty since the production of scholarly publications is a criteria for their respective tenure and promotion processes. Reported results indicate that more academic librarians publish than non-academic librarians; academic librarians working in institutions that are Carnegie ranked Research University - Very High Research (RU-VHR) or Research University - High Research (RU-HR) publish more than those in non-Research institutions; women publish as often as men; and the number of LIS faculty who publish is higher than that of academic librarians in proportion to their respective populations (Budd, 1999; Budd \& Seavey, 1990; Hart, 2000; Joswick, 1999; Watson, 1985; Weller, Wiberley \& Hurd1999; Wiberley, Jr., Hurd \& Weller, 2006). However, each study varies in methodology and with the data sources used. None are based on a theory that would suggest that their results could be replicated or compared to similar studies conducted in the field of LIS, or in other subject fields with empirically valid results.

While Lotka's law of productivity has been tested extensively in the sciences, it has yet to undergo the same type of rigorous study in the humanities, particularly in the field of LIS. There has yet to be a study that closely follows Lotka's methodology to test 
his inverse power law in the field of library and Information Studies. Pao (1985) states, "It would be of interest to demonstrate the general applicability of this relation to authors and their productivity in any subject or in any identified group" (p. 305). This study will investigate whether there is evidence of such applicability in the field of LIS.

\section{Theoretical Framework}

Researchers in the scientific fields have long been studying the productivity of their scholars, starting with Lotka's 1926 seminal study on publication productivity of chemists and physicists. The results of Lotka's study indicated that in the scientific field, 60 percent of authors make a single contribution during a given time period and as the number of contributions by a single author increases, the number of authors decreases. The general formula for the relationship Lotka discovered is expressed as $x^{n} y=$ constant with $y$ being the frequency of persons (authors) making $x$ contributions. Lotka's examination of the data revealed an inverse exponential relationship between the number of persons publishing $x$ articles. In general terms, this relationship has been presented throughout the literature as $1 / n^{2}$, where the number of people producing $n$ papers is proportional (de Solla Price, 1963; Lotka, 1926).

Since the 1940s, Lotka's law has been empirically tested in various subject areas within the scientific field such as engineering, mathematics, psychotherapy, etc. with about the same results (Baker, Robertson-Wilson \& Sedgwick, 2003; Gupta \& Karisiddippa, 1999; Huber \& Wagner-Dobler, 2001; Patra, Bhattacharya \& Verma, 2006; Patra \& Mishra, 2005). For the most part in these studies, Lotka's law did apply to the author's publication productivity. However, Lotka's law has not been tested as widely in the humanities particularly in library and Information Studies. 


\section{Delimitations}

The delimitations for this study are as follows:

1. Only journals in the field of Library and Information Studies indexed in the Institute for Scientific Information (ISI) database product Web of Knowledge (WOK) are included. Librarians published in journals outside this field will not be included in the study.

2. A sample of 28 journal titles that have been previously identified in the library literature as premiere journals in the field were included in the study.

3. Given the vast number of citations indexed by ISI WOK, the study sample uses only a subset of authors whose last names begin with the letters "A" and "B" following Lotka's sampling technique for the Chemistry Abstracts data.

4. Only authors who were indexed (published) during the years 1996 - 2006 are included in the study.

5. The quality of publication content is not taken into account.

6. Authorship affiliation was not taken into account for this study.

\section{Definitions}

Academic Libraries. Libraries that exist within postsecondary institutions with the primary purpose of supporting the research and learning processes that occur.

Bibliometrics. The application of mathematical and statistical methods to books and other media of communication. (Pritchard, 1969, p. 249)

Citation Analysis. Citation analysis uses citations in scholarly works to establish patterns and links between authors, scholarly works, journals, or fields. 
Library and Information Studies (LIS). The umbrella term used by the library profession to include both the traditional aspects of library science and the study of information and its management in the era of technology.

Publication. For the purposes of this study, a publication refers to any written work that has been published in a scholarly journal regardless of length or nature of such work.

Research Libraries. These libraries house collections of national or international significance that are capable of supporting sustained research in a variety of interrelated subjects and of attracting scholars from all over the world. Their primary purpose is to collect and to make available the records of the past, to promote research in them, and to share those materials with scholars and the public

\section{Overview}

A review and analysis of the literature is presented in chapter two. In chapter three, the research design and methodology used to collect and analyze the data is detailed. This chapter will describe in detail the procedures followed as described by Pao (1985) to collect the data was collected. The analysis of the data and results are detailed in chapter four. Conclusions and recommendations are presented in chapter five. 


\section{CHAPTER II}

\section{REVIEW OF RELATED LITERATURE}

In order to better understand the research questions that provide the framework for this study, this chapter will begin with an explanation of Lotka's (1926) study that resulted in Lotka's law. It will also provide a review of its application in the field of library and Information Studies and other subject areas.

\section{Lotka's Law}

Lotka's (1926) seminal study of publication productivity in the sciences has been the catalyst for decades of replicative research conducted in the sciences, but also expanding into the discipline areas of the humanities and social sciences to predict author productivity. His findings indicated that at least $60 \%$ of authors in the sciences published at least one article during their career and there is an inverse exponential relationship between the number of authors publishing $\mathrm{x}$ number of publications.

Lotka used the decennial index of Chemical Abstracts 1907-1916 and the name index of Auerbach's Geschichtestafeln der Physik to determine author publication productivity in the fields of Chemistry and Physics. The volume of author production was determined by counting the number of names in the index of Chemical Abstracts against the number of entries for each name. Lotka counted only authors whose last names began with the letters "A" and "B" totaling 6,891 authors. Then, he omitted the names of firms since they represented an effort of an unknown number of people rather than an individual. It has been noted that the former delimitation was most likely attributed to the enormity of the undertaking since he had to manually record the data. However, the 
sample used was still rather robust given this study took place well before the age of technology. In instances of more than one author, Lotka only credited the senior author. He then plotted the frequencies of authors having published $1,2,3 \ldots$ publications against the numbers (e.g., 1, 2, 3...) of publications as variables on a logarithmic scale. He used a similar procedure for the name index of Auerbach's Geschichtestafeln der Physik, which covers the entire history of publications in the field of physics up to and including the year 1900. This data set included 1,325 persons encompassing all contributors. Lotka noted for the Auerbach data set, "a measure not merely of volume of productivity, but account is taken, in some degree, also of quality, since only the outstanding contributions find a place in this little volume..." (p. 317).

He found that for each set of data the points representing the variables were scattered closely about a straight line on a logarithmic scale having a slope of approximately two to one. The ratio was a closer fit for the Auerbach data, using the first 17 points to determine the least squares. The slope of the curve was found to be $2.021 \pm$ 0.017. The same approach was adopted using the first 30 points of the Chemical Abstracts data, and the slope of the curve was $1.888 \pm 0.007$. Lotka noted that his decision to use the first 17 points of the Auerbach data was due to the "excessive fluctuations" in the data, which was attributed to the limited number of persons in the sample. His general formula for the relationship, found to exist between the two variables, was expressed as

$$
x^{n} y=\text { const } .
$$

He further stated that for the "special case" that $n=2$ the value of the constant is found using the following equation, 


$$
Y_{x}=c / 1^{2}
$$

Unfortunately, many subsequent studies have used the latter formula as a standard equation operating under the assumption that $n=2$ for all data sets. (This will be discussed in depth later in this chapter.) Using this special case, which represents the inverse square law of scientific productivity, it was determined that 60 per cent of all contributors contribute a single item. Lotka's findings showed that $59.2 \%$ of Auerbach's contributors and $57.7 \%$ of contributors appearing in Chemical Abstracts had only one item indexed in each source respectively. Since the exponent values $(n)$ were determined as being approximately the value 2, Lotka summarized his findings as follows:

In the cases examined it is found that the number of persons making 2 contributions is about one-fourth of those making one; the number making $\mathrm{n}$ contributions is about $1 / n^{2}$ of those making one; and the proportion, of all contributors, that make a single contribution, is about 60 percent. (p. 323)

In conclusion, Lotka muses at the similar results he found given the differences in the subject areas, scope, and coverage of the two sources he used. He states,

The fact that two such widely different sources as Chemical Abstracts (listing practically all current work in chemistry over a ten year period) and Auerbach's table (listing selected important contributions only, in physics, for all historical time) give very similar results, seems somewhat remarkable. (p. 323)

Lotka's own recorded reaction to his findings should serve as a catalyst to further inquiry. In fact, he suggests just that by offering the possibility of looking at author publication productivity using another index, Darmstaedter's Handbuch der Geschichte der Naturwissenschaften und der Technik, translated as Darmstaedter's Manual of the History of the Natural Sciences and the Technology. 
Application of Lotka's Law in Library and Information Studies

In the area of bibliometrics, the validity of Lotka's law is still an open question. Although there are many studies throughout the years beginning in the 1940's to test Lotka's law, there is still no conclusive evidence that Lotka's law is empirically valid in the field of science or otherwise. The major reason for this as noted is that researchers have varied widely in their study procedures from Lotka's original study. Thus, their findings are open to dispute due to the lack of consistency in their application of procedures and overall because of a lack of baseline data - other than those presented by Lotka - for reliable comparison.

In 1973, Murphy published his research findings as a Brief Communications in the Journal of the American Society for Information Science. The article entitled, "Lotka's law in the Humanities?" was written with the purpose of testing whether or not Lotka's law can be applied "successfully, predictively to non-scientific productivity?" Murphy's study looked at the first decade of publication for one journal in the "relatively distinctly defined, recent field" of technology called Technology and Culture. He used only scholarly articles and looked at a total of 170 authors (130 of which were single authors). He found that the number of actual contributions did not match up with the predicted number of author contributions.

His method is not clearly detailed, but he states in his results that the data set did comply with Lotka's law. However, based on his discussion he used $n=2$ as the value of his exponent instead of calculating the exponential value using the data. This faulty calculation alone causes the results of his study to be deemed unreliable. Murphy also did not conduct a goodness-of-fit test. 
Schorr (1974) tested the application of Lotka's law to publications appearing in two library journals, Library Quarterly $(L Q)$ and College \& Research Libraries $(C \& R L)$ for the period 1963-1972. A total of 618 contributions were studied which included 210 articles from $L Q$ and 408 articles from $C \& R L$.

He found that the data distribution strayed from Lotka's in that instead of authors with two articles accounting for 25 percent of single authors entries, they accounted for only 4.6 percent in each journal. Schorr concluded that Lotka's law does not apply to the field of library science where "four-fifths of all papers represent the only contribution of an individual" (p. 33). He suggested that Lotka's formula be altered to read $\frac{1}{n^{4}}$ whereby for each 100 contributors of single articles about six will contribute two articles, about one will contribute three articles, etc.

Schorr compared his findings based on the assumption that the value of the exponent $n=2$ in Lotka's general formula, instead of calculating the value of the exponent from his data set. Secondly, his study is limited to two journals and a small sample size which further compromises the reliability of his findings and conclusions.

In 1977, Coile published an article refuting the findings of Murphy's (1973) and Schorr's (1974) studies of Lotka's law in the humanities and map librarianship respectively. Coile noted that Murphy did not use Lotka's precise formula, which includes a constant and inverse square component, instead Murphy calculated an "ideal" number. Coile further noted that Murphy also used the actual number of single authors as the basis for calculating the predicted number (rounded off) of authors with two articles, instead of the total number of authors as his base as did Lotka. This researcher would 
note further that Murphy included only scholarly articles and counted co-authors in his study whereas Lotka did not note such a distinction in his procedures and counted one author in cases of co-authorship.

In the same article, Coile (1977) addresses the 1974 study conducted by Schorr applying Lotka's law in map librarianship. Schorr like Murphy tested Lotka’s law in a field outside of science. Schorr's study looked at a 10-year span of publications in two premier LIS journals, Library Quarterly and College \& Research Libraries for his study that included a total of 408 contributors. Schorr's (1974) findings that Lotka's law does not apply to the field of library science and suggests that perhaps for library science literature

scholarly production would follow an inverse quadruple power law whereby for each 100 contributors of single articles, about 6 will contribute two articles, about 1 will contribute three articles and almost no writers would provide four articles or more. (p. 33)

Coile noted that Schorr included co-authors in his total author count and used a chi-square goodness-of-fit test. In his opinion, Coile felt that the results from both Shorr's and Murphy's findings were not empirically valid based on their deviance from Lotka's formula and procedures this opinion was concurred by subsequent Lotkaian researchers (Nicholls, 1989; Pao, 1985; Potter, 1981)

While examining the changes that occurred during the publication of one of the field's premier journals, College \& Research Libraries (C\&RL) Cline (1982) also looked at the citation patterns of authors contributing to the journal, from $1939-1979$. A total of 1,240 principal authors contributed 1,775 articles to $C \& R L$ during this 40 -year period resulting in an average of 1.43 articles per author. 
After testing Lotka's law using the data from $C \& R L$, she found that 80 percent (992) of the principal authors studied made a single contribution to $C \& R L$. The calculated values for $n$ and $c$ for this data set were $n=2.44$ and $c=.5129$ respectively. Results from the K-S goodness-of-fit test at the .01 level of significance indicated that the data did not adhere to Lotka's law. She therefore concluded that it was "obvious....that librarians were not as productive as scientific authors..." (p. 213); an erroneous conclusion given the limitation of the study to one journal title with a focused library audience.

In examining the publication trends of academic librarians to see whether or not their publication productivity conforms to Lotka's law, Budd and Seavey (1990) looked at citations in 36 LIS journals for a period of five years, 1983-1987. Only full-length articles were included in the studies. Co-authors were credited fractionally based on the number of authors. A total of 1,656 articles written by 1,373 different individuals were reviewed. Only 1,027 librarians had one article attributed to their name and 128 individuals were identified as either sole or co-authors with more than two articles each. The researchers found that the data did not conform to Lotka's law. In fact they found the deviation from the expected values to be "quite severe" (p. 465). Their findings showed that approximately $75 \%$ of academic librarians produced at least one publication as opposed to $60 \%$, which resulted in a much steeper decline in productivity than anticipated by Lotka.

As Pao (1985) later suggests, Budd \& Seavey's findings may have been adversely affected by their deviation from Lotka's procedures. Instead of attributing credit to only the senior author (most often the person listed first), the researchers apportioned credit amongst all co-authors. Additionally, they used a limited time period of five years as 
compared to Lotka's use of indices that covered 10 years and the entire history of a subject up to 1910 respectively. The limitation of timespan poses a severe limitation for one to accurately anticipate an author's publication productivity and results in their findings being suspect.

Pao (1985) used 48 data sets taken from previous tests of Lotka's law representing 20+ subject areas, and where necessary, recast the data to meet the procedures established by Lotka. She found that when the data sets were tested using the same exact procedure followed by Lotka, the majority of these data sets conformed with Lotka's law. Only nine data sets of data did not fit the law. Her study indicated that the law appears to be insensitive to timeframes. However, there is sensitivity to the number of primary sources used to collect the data. For example, single sources in a limited timeframe (e.g., one year) may not produce favorable results as authors may not send all their publications to a single journal in a given year. She suggests that "data be compiled from a comprehensive source" in order to capture a true representation of author publication using either quality or quantity as a selection criteria. She further suggested using a longer period of coverage, if only a single primary journal is used to collect data.

Nisonger (1996) studied authorship in the journal, Library Acquisitions: Practice \& Theory (LAPT), for a period of eighteen years (January 1977 - Winter 1995). This was a journal based study focusing on the articles found within the publication. The intent of the study was to identify authorship patterns not necessarily author publication productivity in library and Information Studies journals. The study findings indicated that over $80 \%$ of the authors published in LAPT contributed a single article and a fraction under $4 \%$ contributed four or more articles. While Lotka's law was not stated as a part of 
his research purposes, Nisonger introduces Lotka's law in the discussion of his findings and states that his data does not conform to Lotka's law. A finding to the contrary would have been highly questionable given the study design and method, which does not follow Lotka's original design and the limitation of the data set, which focused on one journal title.

Bonnevie (2003) presents an analysis of the Journal of Information Science (JIS) focusing on the previous 25 years using the ISI's citation databases. The research methods employed were a combination of publication and citation analysis along with Lotka' Law. The findings indicated that JIS was represented by 6,953 items in 24 databases, with only 1,673 unique items. Since Social SciSearch (SSCI) and LISA had the most indexed items for JIS, Bonnevie then looked at the items unique to these databases. Further analysis found that 2,140 JIS publications in the two databases. To test the data set for Lotka's law, Bonnevie, conducted a search in SSCI and LISA resulting in 1,326 different authors - including co-authors. Correcting the data for variant names of the same author reduced the data set to 1,270 items. Using a program by Rousseau and Rousseau the observed frequency data are tested for Lotka's law. The distribution of authors with more than one article and authors with one article was $26 \%$ to $74 \%$. Bonnevie concludes that the distribution pattern of JIS complies with Lotka's law, with fewer authors writing more than one article than expected.

The results of this study like many of its predecessors are suspect since co-authors were included in the author count. In the discussion of the findings, Bonnevie also misstates that, "Lotka discussed the general law and the square law (exponent $=2), \ldots$ " (p. 15). In fact, Lotka (1926) did not assign the value $n=2$ (where $n$ represents the 
exponent value), he merely states, "For the special case that $n=2$ (inverse square law of scientific productivity..." (p. 320) indicating that when the slope of the logarithmic curve is calculated to be $n=2$ the inverse square law applies.

Patra, Bhattachraya, and Verma (2006) conducted a bibliometric study of the literature on bibliometrics using data from the Library and Information Science Abstracts (LISA). The data set used for this study included 3,781 records and covered the dates from 1969 to September 2005.

These researchers found that about 4,000 authors published 3,781 articles - about 0.94 articles per author indicating that single authorship is very common in this field. Approximately 3,106 (77.65\%) authors have only one publication and $470(11.75 \%)$ have only two publications. Using a modified formula given by Pao (1985) and Fang (1995) the values of $c$ and $n$ for bibliometrics literature were found to be 0.64 and 2.09. The Kolmogorov-Smirnov test shows that bibliometrics literature does not follow Lotka's law. Even thought the researchers state that single authorship is common in the field. It is not clearly detailed whether or not co-authors were included in the author count. This small detail weighs heavily on the reliability of the findings.

Patra and Chand (2006) conducted a bibliometric study of Library and Information Science research in India. They collected their data from the online version of the Library and Information Science Abstracts (LISA). The LISA database covers $440+$ periodicals, over 68 countries and 20 different languages. The researchers limited their results to the years $1967-2004$ and to records containing the term "India". A total of 3,396 records were used in the study. 
When testing Lotka's law they found that in Indian LIS literature $74 \%$ of the authors have one publication, about $12 \%$ have two publications and $4 \%$ have three publications. They found the value of the exponent $n$ to be -2.12 and the value of the constant, $C$ is 0.64 . The results of the K-S test indicated that Indian LIS literature follows Lotka's original distribution.

What remains unclear about this study is whether or not the researchers attributed publications to single authors or to co-authors as well. This seemingly inconsequential procedural matter makes a difference in the perceived reliability of the results as it digresses from that taken by Lotka.

\section{Application of Lotka's Law in Other Disciplines}

MacRoberts and MacRoberts (1982) examined Lotka and Price's data base to test the generalizations espoused by Price, "Fifty [sic] percent of scientific publications are produced by 6 percent of the scientific community" and his calculation that the average scientist produces only about three papers in his/her lifetime" (p. 444). The researchers did not have access to the same indices used by Lotka, so they used what they felt were comparable data sources Biological Abstracts (BA) and Psychological Abstracts (PA). They soon realized that using these sources provided three significant limitations: (a) incomplete coverage, (b) $B A$ and $P A$ do not abstract everything appearing in the journals monitored, and (c) because the abstracting services in their attempt to be widely inclusive, results in a large number of low producers being included.

Instead of proceeding with the above method they tested their own interpretation of Lotka's and Price's statistics stated as follows, “they [statistics] may represent individual productivity in particular fields, not total individual productivity." To test their 
hypothesis they used 956 senior authors listed in the bibliography to Ernst Mayr's Animal Species and Evolution, considered a classic survey of the biology and genetics of animal species. Following the same procedure used by Lotka to account for author productivity they achieved the same results as Lotka. However because of their familiarity with the field, they recognized that the publication counts of only a few individuals were represented by the bibliography. They used Darwin and Mayr as examples of individuals whose publication productivity based on this bibliography appeared lower than it really was. Their rationale for low producers in a given field may be due in fact to low productivity, or they were peripheral to the field, new to the field, or had moved out of the field. Further, the narrower the field the fewer numbers of authors whose complete bibliographies were represented in addition to a higher number of single publications.

While MacRoberts and MacRoberts achieved the same findings as Lotka, the results of this study are open to question based on the single data source used to represent an entire field. Although this bibliography is included in a classic work, it is not clear if this work is actually representative of an entire field, nor is there any information on the scope of this source. It is not apparent to this researcher if the work covers the subject area from it's inception to the time of the work being published. Since the timeframe of the data for this study remains unknown, the results do not provide conclusive evidence to support MacRoberts and MacRoberts hypothesis.

Gupta and Karisiddippa (1999) explored the possibility of using a new variable, $k$ representing the number of collaborating authors as a substitute for the number of papers in Lotka's distribution to predict productivity (p. 132). The revised Lotka's formula would appear as: 


$$
Y_{k}=c / k^{n}
$$

The study data was extracted from the Bibliography of Theoretical Population Genetics, $(B T P G)$ which according to the authors is a comprehensive bibliography compiled by Felsentein in 1981. The bibliography covers the subject area of theoretical population genetics from 1870 to 1980 . The total number of authors contained in this source is 3,209 with 7,880 papers.

In contrast to Lotka's procedure for giving author credit, Gupta and Karisiddippa used the normal count method to evaluate the productivity of authors. That is they gave every author - including co-authors - one credit, whereas Lotka credited only the senior author. They found a positive, although not a strong relationship between the two variables - number of papers and the average number of collaborators per author. Testing both the derived figures for the number of collaborative authors and percentage of collaborative authors Gupta found that results of both did not conform to Lotka's law and so the new variable $k$ was not appropriate.

Saam and Reiter (1999) attempted to test a new model for measuring publication productivity based upon Lotka's law. The proposed dynamical model takes into account the evolution of the publication and the citation distributions over the histories of scientific fields, using both simulated and real historical data. The simulated data were produced using a simulation language called Micro and Multilevel Modeling Software (MIMOSE) that was under development at the Department of Social Science Informatics in Koblenz/Germany. The new model incorporates eight variables: Write, utility, publications, citations, field, reputation, state and active. 
For the simulation model the researchers used the journal Systeme using 80 scientists. The researchers collected and analyzed the empirical data from several German and Austrian scientific journals on family therapy and psychotherapy. Two of the four data sets studied focused on publications that include all authors and co-authors from the journal Psyche (1947 - 1992) and authors in the entire field of German-language systemic family therapy, which includes seven journals (Familiendynamik, Kontext, Partnerberatung, Systhema, System Familie, Zeitschrift fur systemische Therapie, 19761995) (p. 149). They specified that only "proper articles" were included (p. 149), but there is no context from which to determine what is meant by the term proper article. Although they state that their simulated coefficients of skewness are somewhat smaller than the empirical ones for the whole field of systemic family therapy, they assured that a visual inspection or "face validity", of an observer would not be able to find a difference between the empirical and simulated data, nor to a graphical representation of Lotka's law.

The title of this article, "Lotka's law Reconsidered" is a misnomer. The primary purpose of this study was not to test Lotka's law in the field of family therapy but rather to test a new model of publication productivity that included a variety of variables that measured productivity on a number of levels. In the procedures the researchers mention they only included "proper articles" and although they never define what is meant by this, any filtering of the articles would affect the author count. This would lead to the deviation from Lotka's study thereby rendering any absolute findings comparable to Lotka's law not valid. Although the Saam and Reiter state that a visual inspection of their 
findings would mirror the graphical representation of Lotka's law, they do not state that their findings support Lotka's law.

Baker, Robertson-Wilson, and Sedgwick (2003) studied the publication record of five sport psychology journals. Articles published in the International Journal of Sport Psychology (IJSP), the Journal of Sport \& Exercise Psychology (JSEP), The Sport Psychologist (TSP), The Journal of Sport Behavior (JSB), and the Journal of Applied Sport Psychology (JASP) from 1970 to 2000 were included. They did not include abstracts associated with conference proceedings and book/video reviews. This journalbased study was purported to provide support for the Lotka-Price Law which according to the researchers "Predicts that the top $10 \%$ of researchers should account for $50 \%$ of the published papers" (p. 480).

Baker, et al identified the top 2,517 unique authors from all the journals examined. However, they present their results in terms of total number of authors $(5,206)$ which includes multiple author counts. They found that approximately $24 \%$ of the articles published in the field of sport psychology were produced by $3 \%$ of the publishing researchers. Additionally, they were able to identify that the top $10 \%$ of the researchers in the field produced nearly $44 \%$ of all the papers produced.

The shortcoming of this study is that the results are calculated using the total author count, which is a summation of all the authors appearing in each journal title examined. This results in multiple counts for the same author, whereas in Lotka's study the authors were counted once and their publications were attributed multiple times. Secondly, the researchers acknowledge a Lotka-Price law; however, when the researcher investigated the source cited for this Law, it became apparent that it should really be 
called the Lotka-Dennis law (Price, 1963, p. 41), if there is to be a name applied to the phenomena that they are testing

Rai and Kumar (2005) investigated literature in bioinformatics using a number of bibliometric techniques including Lotka's law. Their data set was drawn from the PubMed database and analyzed to identify the core journals in the field. An exact timeframe was not clearly stated for the 16, 471 records retrieved from this database and examined, as the researchers only provide an end date of January 2005 . One can assume that the data set includes all records from the founding of the PubMed database to present. Applying Bradford's law, the researchers established that there are at least 20 core journals in this growing field. Only the first author was counted for co-authored publications accounting for a total of 39,435 authors. They calculated that 29,008 authors published only one article (73.58\%) and approximately $20 \%$ of remaining authors published two to three articles.

According to their findings, authors in the bioinformatics field seem to be more on the productive side with $23 \%$ of the authors producing one article instead of the predicted $60 \%$. Only $5 \%$ proved to be highly productive having published more than ten articles. According to the researchers a Kolmorogov-Smirnov goodness-of-fit test indicated that the authors' productivity pattern followed Lotka's law. Although the researchers assert that their calculated $c$ and $n$ values (0.78 and 2.69 respectively) fit the values found by Lotka's study, this assertion is somewhat exaggerated since Lotka's calculated $c$ and $n$ values for his data sets were 0.60 and approximately 2.0. 


\section{Summary}

A review of the literature indicates that Lotka's law has been tested throughout the years in a variety of subject areas and disciplines with only a few studies having been conducted in the field of Library and Information Studies. However, the majority of the results of these studies have deviated from Lotka's original procedures rendering the results useless as a sound basis for validating or disproving Lotka's law. The studies, subject areas (or journal titles) covered and results are presented in Table 1. The following chapter will detail the process proposed by Pao (1985) copying that of Lotka's, which will be used to test Lotka's law in the Library and Information Studies.

Table 1

Studies Cited

\begin{tabular}{lclcc}
\hline & & & \multicolumn{2}{c}{$\begin{array}{c}\text { Lotka's } \\
\text { law }\end{array}$} \\
\cline { 2 - 6 } Author(s) & & $\begin{array}{l}\text { Subject Area/ } \\
\text { Murphy }\end{array}$ & Y & N \\
Schorr & 1973 & Humanities & X \\
Schorr & 1974 & Map Librarianship & & X \\
Coile & 1975 & Legal Medicine & & X \\
Cline & 1977 & Humanities and Map Librarianship & & X \\
MacRoberts \& MacRoberts & 1981 & College \& Research Libraries & & X \\
Pao & 1982 & Science & X & \\
Budd and Seavey & 1985 & Science & X & \\
Nisonger & 1990 & Library \& Information Studies & & X \\
Gupta \& Karisiddippa & 1995 & Library Acquisitions Practice \& & & X \\
Saam \& Reiter & 1999 & Theory Journal & & X \\
Baker, Robertson-Wilson $\&$ & 1999 & Family Therapy \& Psychotherapy & & X \\
Sedgwick & 2003 & Sports Psychology & X & \\
Bonnevie & 2003 & Journal of Information Science & X & \\
Patra \& Mishra & 2005 & Bioinformatics & X & \\
Patra \& Chand & 2006 & Library and Information Science & X & \\
Patra, Bhattachraya \& & 2006 & Bibliometrics & & X \\
Verma & & & & \\
\hline & & & & \\
\hline
\end{tabular}




\section{CHAPTER III}

\section{METHOD}

This chapter describes the strategies used to examine the applicability of Lotka's law of publishing productivity in Library and Information Studies (LIS). It follows the methodology recommended by Miranda Pao (1985), which follows the original methodology employed by Lotka (1926), to test the compliance of library and Information Studies authors to Lotka's inverse power law of author publication productivity.

The research questions addressed in this study were:

1. To what extent can Lotka's law be used to predict publication productivity in the field of Library and Information Studies?

2. What are the characteristics of the high producing LIS authors based on the available data?

A description of the research design, data source, hypothesis, data procedures, treatment of data and summary are provided in this chapter.

\section{Design}

The design used in this study was set up to examine the goodness-of-fit of a theoretical distribution of publications obtained using a formula derived by Lotka (1926) and an actual distribution of publication of librarians obtained from the ISI Web of Knowledge. This study used an ex post facto design, since the "manifestations of the independent variables in the study have already occurred" or are not manipulable (Black, 2003, p. 70). The predictor variable was the number of publications predicted by Lotka's equation. The criterion variable was the number of citations of authors in library science and Information Studies journals found by searching the Science Citation Index, Social 
Science Citation Index and the Arts and Humanities Citation Index databases using specified criteria (i.e., time period, authors' last names and limited journal titles).

Procedure and Data Analysis

\section{Data Collection}

The sample of citations was collected from Thomson Scientific's ISI Web of Knowledge database. This aggregated database allowed the researcher the ability to search across indices (Science Citation Index, Social Science Citation Index and the Arts and Humanities Citation Index) with one search. When conducting the search, the advance search option was used in order to limit the search results to the 25 LIS journal titles listed in Table 2. These journal titles have been the focus of a number of studies looking at publication patterns of U.S. Academic Librarians from 1998-2006 (Budd, 2006; Budd \& Seavey, 1996; Buttlar, 1991; Hart, 2000; Joswick, 1999; Krausse \& Sieburth, 1985; Watson, 1985; Weller, Hurd \& Wiberly, 1999; Wiberly, Hurd \& Weller, 2006).

The search was further refined by limiting the publication timeframe to 1996-2006 and by searching the author field for last names beginning with the letters "A" and "B". The results list was checked to ensure that the citations accurately reflected the search query. A total of 7,070 citations were saved in batches as comma delimited files (CSV) and exported into Excel for data cleansing. As in Lotka's study, only the first name in the case of collaborative authorship was counted therefore co-authors were deleted and the articles authored by organizations were omitted since they represented a group effort. A good faith effort was made to identify individual authorship in instances where authors' 
names appeared multiple times with slight variations (e.g., M.L.S. Smith versus M.S.

Smith or M. Smith) to ensure that a proper

Table 2

Library and Information Studies Journal Titles Used in Study

Titles

American Archivist

Behavioral and Social Sciences Librarian

Bulletin of the Medical Library Association

Journal of the Medical Library Association

College \& Research Libraries

Government Information Quarterly

Information Technology \& Libraries

Journal of Academic Librarianship

Journal of Education for Library and Information Science

Journal of Government Information

Journal of the American Society for Information Science

Journal of the American Society for Information Science and Technology

Libraries \& Culture

Library Acquisitions: Practice and Theory/Library Collections, Acquisitions, and Technical Services

Library and Information Science Research

Library Hi Tech

Library Quarterly

Library Resources \& Technical Services

Notes: Music Library Association

Online \& CD-ROM Review

Online Information Review

Reference \& User Quarterly

Science \& Technology Libraries

Serials Librarian

Technical Services Quarterly 
count was recorded by reviewing the full citation record in the ISI WOK database to determine the author's affiliate institutions. If the affiliate institution matched both name variations for the publications in question, it was attributed to a single author. In cases where authors' names appeared the same, but their affiliate institutions were different the publications were attributed to each individual author. This process was totally dependent on the accuracy and thoroughness of the database records. Any resulting discrepancies are attributed to the limitations of the indexing and abstracting practices of ISI WOK.

\section{Calculating the Values for $n$ and $C$}

The data were then arranged in a table to determine frequency distribution. After the data cleansing process the publications of 610 authors with the last names beginning with the letter "A" and 1,246 authors with names beginning with the letter "B" were included analyzed in this study. Following the steps detailed by Pao (1985), the data were arranged in a table with the first two columns containing values of $x$ (number of contributions) and $y$ (frequency of authors) arranged in increasing order of productivity. The table was then expanded into six columns, with columns three and four containing $X$ and $Y$ respectively, where $X=\log x$, and $Y=\log y$. The values for $X Y$ and $X^{2}(X X)$ were appear in columns five and six. See Appendix A for the full data set.

The next step was to calculate the value of $n$ for this data set. The least-square method was used to compute the "best" value for the slope $n$, which is the exponent for Lotka's law. The values of $Y$ were plotted against $X$ (y-axis) and then visually inspected to determine the approximate end of the straight line to determine the region of cutoff of the 
high producers (see Figure 1). Since high producing authors would skew the data, Lotka chose to omit these authors from his analysis. In a footnote, Lotka explains his decision stating, "The very high figures (e.g., Abderhalden, 346 contributions in ten years) should perhaps be considered separately, since they are not the product of one person unassisted...." (p. 323). In order to select the cases to be omitted, Lotka plotted the values on $\log$ on log paper and visually inspected the straight line to determine the cutoff point. Following Lotka's example, the most prolific authors have also been excluded from the analysis of the current data.

Pao (1985) suggests that Lotka's original method of visually ascertaining the cutoff point may not be the most accurate way possible of determining the number of cases to use for future studies. She offers that in addition to the visual inspection of the $\log$ on $\log$ plotting, one must also calculate the value of $n$ using various data points. In this data set, it was determined that publication productivity became more sporadic after the 18 th point (See Appendix A) with fewer numbers of authors producing large number of publications. See Figure 1 for the plotted data and Table 3 for the values used to calculate the value of $n$ for the first 18 points.

The formula for the least squares method used to calculate the slope of $n$, the exponent, was as follows:

$n=\frac{N \sum X Y-\sum X \sum Y}{N \sum X^{2}-\left(\sum X\right)}$ 


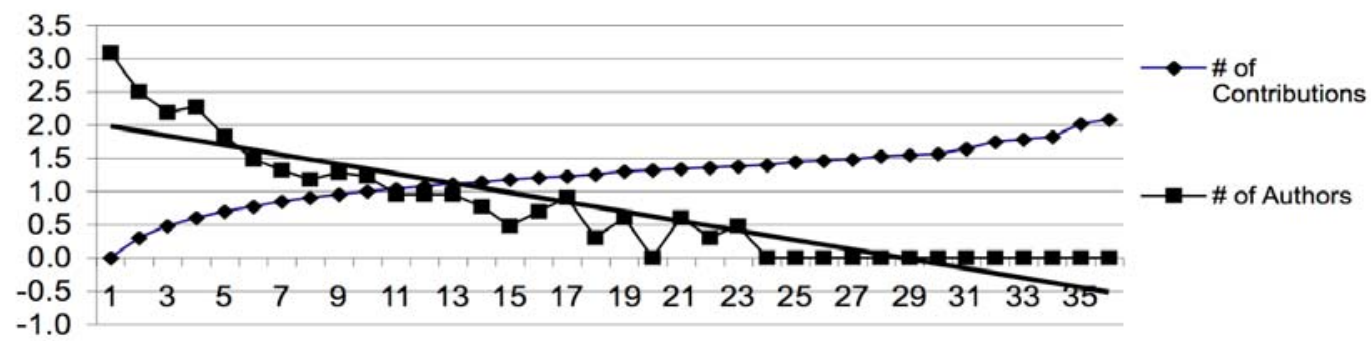

Figure 1. Logarithmic chart plotting \% of authors producing \# of publications.

Using the value of $n$, the next step was to calculate the value of $C$. While most researchers have chosen to use the simpler calculation method using the value of $n=2$ (Budd \& Seavey, 1990; Coile, 1977; Murphy, 1973; Schorr, 1974, 1975), Pao (1985) notes that this procedure is neither accurate nor appropriate to use when the calculated valued of $n \neq 2$. Pao (1985) states, “...for other non-negative fractional values of $N$, the summation of the series in its general form, $\sum 1 / x^{n}$, may only be approximated by a function which calculates the sum of the first $P$ terms" (p. 310). Although Lotka (1923) referred readers to a footnote (p. 320) that cites Coolidge's (1924) "Mathematical Theory of Probability" to provide an explanation of how the summation is calculated when the exponent is fractional, like Pao (1985, p. 310), this researcher did not find such an explanation in this source. However, further investigation by Pao revealed that there is no easy formula for computing the sum of an infinite series, therefore with the help of a colleague she followed Lotka's equation, $C=1 /\left(\sum 1 / x^{2}\right)$. Pao and her colleague derived a formula approximating the summation $\sum 1 / x^{n}$ for non-negative fractional values of $n$. 
It was found that the residual error was neglible when $P$ is set to 20 . The equation representing their resulting approximation is

$$
\sum_{x=1}^{\infty} \frac{1}{x^{2}}=\left[\sum_{x=1}^{P-1} \frac{1}{x^{2}}+1 /(n-1)\left(p^{n-1}\right)+1 / 2 p^{2}+n / 24(p-1)^{n+1}\right]
$$

Using $P=20$, Pao (1985) checked the calculated summation with the values $n=2$ and $n=4$ and found that the error was less than $1 / 110,000$ and $1 / 25,000,000$ respectively. Additionally, Pao compared Lotka's value $C$ for his chemistry data using $n$ $=1.888$ and $P=20$ in the calculated summation and achieved the same results as Lotka, $C$ $=0.5669$. For this study the researcher followed Pao's equation and used the value $n=$ 2.1 and $P=20$ into equation (2).

\section{Conducting a Goodness-of-Fit Test}

Lastly, the observed and known data were tested for goodness-of-fit using the one-sample Kolmogorov-Smirnov (K-S) test. The K-S goodness-of-fit test was used to compare the functions describing the observed and theoretical distributions of publication by the academics whose records were examined. Early studies have used either the Chisquare or the K-S goodness-of-fit tests when testing data conformity to Lotka's law. However, recent studies (Budd \& Seavey, 1990; Cline, 1981; Coile, 1977; Pao, 1985) have employed the K-S test because it is seen as the most powerful test available (Black, 2003; Nicholls, 1986; Pao, 1985). Black (2003) notes the K-S test is more powerful than the $\chi^{2}$-test, and is an appropriate test for ranked data. The K-S test assumes an underlying continuous distribution and compares the cumulative distribution of the data with that for 
the expected population distribution. Since one of the goals of this study is to prove that the observed distribution is not different from the distribution predicted by Lotka, one has a greater potential to reject the null hypothesis testing at the .10 level of significance.

Since the sample size was greater than ten, but less than 25 , the critical value was calculated at the 0.10 level of significance using the following equation provided by Black (2003, p. 567):

Critical value $=1.22 / \sqrt{n+1}$

\section{Hypothesis}

The results of numerous studies concerning the applicability of Lotka's law to the publication productivity of authors in various fields have experienced very similar results to that of Lotka. Therefore, this study was conducted with the following hypotheses in mind:

There is no significant difference in the distribution of publications by authors between what was predicted by Lotka's law and the distribution obtained empirically from the citation indices.

\section{Summary}

Using the ISI Web of Knowledge databases, citations of publications with the primary author's last name began with the letters "A" and "B" for the years 1996-2006 were downloaded into a spreadsheet, sorted, and then counted. The data were then arranged in ascending rank order presenting the number authors $(y)$ who produced $x$ number of publications. The value of the exponent $n$ and the constant $c$ was calculated in 
Excel. The K-S goodness-of-fit test was conducted to ascertain the validity of Lotka's formula when predicting publication productivity in LIS. 


\section{CHAPTER IV}

\section{ANALYSIS AND RESULTS}

In this chapter the data analysis process used to address each research question is provided in detail. In order to find out to what extent Lotka's law can be used to predict publication productivity in the field of Library and Information Studies, the procedure detailed by Pao (1985), was used to test the citation data compiled from LIS journals indexed in ISI WOK. Characteristics of the highest producing authors are also provided.

\section{Data Analysis for Research Questions}

\section{Research Question 1}

Research question one asks to what extent can Lotka's law be used to predict publication productivity in the field of library and information studies. The testing procedure detailed by Pao (1985) was used to address this question. Pao's suggested table of distributed values used to calculate the value of the constant $C$ is presented in Table 3 .

The slope of $n$, the exponent for Lotka's law, was calculated using the least squares method illustrated by equation (1) and the values for the first 18 points shown in Table 3. The calculated value of $n$ for this data set is $n=-2.1$. The full distribution table for all 122 cases is provided in Appendix A. Lotka's inverse power law is evidenced as one can clearly see that while the number of publications increases, the number of authors producing said number of publications decreases indicating. The most prolific author in this dataset produced 122 publications and the next most prolific author produced 105 publications. However, these figures do not speak to the quality or the 
nature, or type of publications (e.g., research, book reviews, etc.) counted, they are simply descriptions of productivity.

Table 3

Calculation of $n$ for the First 18 Points Using Pao's Suggested Table

\begin{tabular}{cccccc}
\hline$x$ & $y$ & $X=\log x$ & $Y=\log y$ & $X Y$ & $X X$ \\
\hline 1 & 1227 & 0.00000 & 3.08884 & 0.00000 & 0.00000 \\
2 & 318 & 0.30103 & 2.50243 & 0.75331 & 0.09062 \\
3 & 155 & 0.47712 & 2.19033 & 1.04505 & 0.22764 \\
4 & 188 & 0.60206 & 2.27416 & 1.36918 & 0.36248 \\
5 & 68 & 0.69897 & 1.83251 & 1.28087 & 0.48856 \\
6 & 30 & 0.77815 & 1.47712 & 1.14942 & 0.60552 \\
7 & 21 & 0.84510 & 1.32222 & 1.11740 & 0.71419 \\
8 & 15 & 0.90309 & 1.17609 & 1.06212 & 0.81557 \\
9 & 19 & 0.95424 & 1.27875 & 1.22024 & 0.91058 \\
10 & 17 & 1.00000 & 1.23045 & 1.23045 & 1.00000 \\
11 & 9 & 1.04139 & 0.95424 & 0.99374 & 1.08450 \\
12 & 9 & 1.07918 & 0.95424 & 1.02980 & 1.16463 \\
13 & 9 & 1.11394 & 0.95424 & 1.06297 & 1.24087 \\
14 & 6 & 1.14613 & 0.77815 & 0.89186 & 1.31361 \\
15 & 3 & 1.17609 & 0.47712 & 0.56114 & 1.38319 \\
16 & 5 & 1.20412 & 0.69897 & 0.84164 & 1.44990 \\
17 & 8 & 1.23045 & 0.90309 & 1.11121 & 1.51400 \\
18 & 2 & 1.25527 & 0.30103 & 0.37787 & 1.57571 \\
\hline Total & 2109 & 15.80634 & 24.39399 & 17.09828 & 15.94158 \\
\hline
\end{tabular}

Using equation (2) the value of $C$ was calculated for this data set resulting in

$\sum 1 / x^{2.1}=1.558149$

$C=1 / 1.558149$

The computed value of the constant $C$ in the current data set is $C=0.6418(64.18 \%)$, which is very close to Lotka's calculated values of $C$ (56.69\% and $60.79 \%$ respectively) for the Chemical Abstracts and Auerbach data. This figure indicates that 
Table 4

K-S Test of Observed and Expected Distribution of Authors

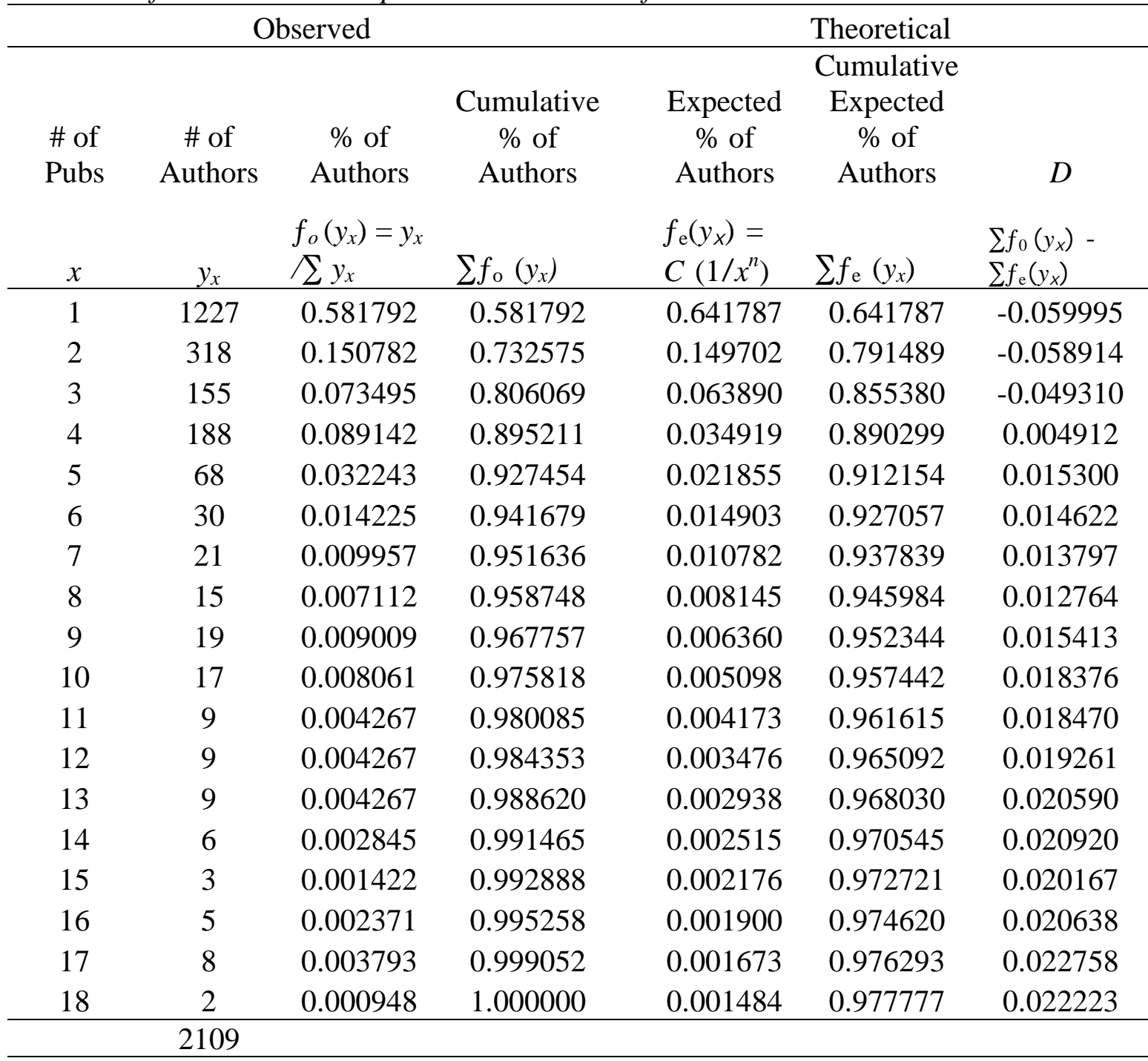

the proportion of contributors who publish a single item in the field of LIS is just over 64\%. The observed percentage of authors publishing two articles is $15 \%$ and the number publishing three articles is $7 \%$ and so on. Looking at the expected percentages of publications in Table 4 one can see that the predicted values closely match the observed 
values indicating that $64 \%$ of authors in LIS will publish one article, about $15 \%$ percent will publish two articles and $6 \%$ will publish three articles.

The K-S goodness-of-fit test was conducted to determine if Lotka's law can be used as a reliable tool to predict author publication productivity from the observed values. Looking at the D column in Table 4, the maximum difference between the cumulative distributions, $D_{\max }$, is 0.022758 . The critical value was computed using equation (3),

Critical value $=1.22 / \sqrt{2109+1}$

$=0.026562$

The resulting critical value is 0.0265621 . Since the critical value is greater than the $D_{\max }$, (0.022758), we must fail to reject the null hypothesis that the distribution is not different from the distribution predicted by Lotka's law using the formula $\mathrm{x}^{2.1} * y_{x}=0.6418$.

\section{Research Question 2}

Table 5 presents the five highest producing authors in this study, providing the number of publications for each, their institution affiliation and their last publication date based on the information provided by ISI WOK. The most prolific author, R. Anderson produced 122 publications and the second most productive author, B. R. Boyce published 104 publications during the 10-year period studied. All of the authors are affiliated with institutions that are Carnegie Classified as either a Research University with high research activity (RU/H) or a Research University with very high research activity (RU/VH). The last publication date column shows the year of the most recent citation. 
Table 5

The Top Five Most Productive Authors

\begin{tabular}{llll}
\hline Name & $\begin{array}{l}\text { \# of } \\
\text { Publications }\end{array}$ & Institution* & $\begin{array}{l}\text { Last Publication Date } \\
\text { (as of 9/2007)** }\end{array}$ \\
\hline Anderson, R. & 122 & University of Nevada, Reno & 2006 \\
Boyce, B. R. & 104 & Louisiana State University & 2000 \\
Bullard, S. R. & 66 & Kent State University & 1996 \\
Burge, D. & 61 & University of Rochester & 1991 \\
Ambrose, J. P. & 56 & University of Vermont & 1997
\end{tabular}

*Last known institution based on information provided by ISI WOK.

**B Based on information provided in citation accessed via ISI WOK.

Results

One may question the results of this study by remarking that the sample is merely a subset of the total publications produced by authors in the area of library and information studies during the specified timeframe and while that is a correct statement Nicholls (1987) points out that the testing of Lotka's law using subsets "from properly compiled data can be representative of the population" (p. 97). Although Nicholls does not define what he means by the phrase "properly compiled" this study has taken into consideration the following recommendations of previous researchers which includes: (a) crediting the lead author with a publication (Lotka, 1926; Pao, 1985; Potter, 1981; Nicholls, 1987) ; (b) using a sizable sample consisting of over 1,000 cases (Huber \& Wagner-Dobler, 2001; Pao, 1985; Potter, 1981); (c) collecting data from a lengthy time interval (Huber \& Wagner-Dobler, 2001; Pao, 1985; Potter, 1981); (d) using a source 
that is sufficient in breadth and scope (Lotka, 1926; Pao, 1985; Potter, 1981; Nicholls, 1987); and (e) calculating the values of $n$ and $c$ for each data set rather than using the value $n=2$ (Lotka, 1926; Nicholls, 1987; Pao, 1985; Potter, 1981).

Previous researchers (Coile, 1977; Nicholls, 1987; Pao, 1985; Potter, 1981) have noted that many of the studies testing Lotka's law vary widely in their procedures producing questionable results. One such variation includes trying to attribute credit to collaborating authors. Some studies have used fractional attribution (i.e., divvying the one publication by the number of authors), and some have attributed one publication to each collaborative author. Lotka (1926) only attributed credit to the lead authors in his study. It is believed this was done because of the difficulty in identifying collaborating authors in the Auerbach index and secondly, simply because of the extensive amount of time it would have taken him to do so in the pre technology era. Potter (1981) notes:

A look at the first decennial index to Chemical Abstracts revealed that if an article has four or fewer authors, all authors are indexed. However, the second, third and fourth authors will only have a 'see' reference to the first author. A sample showed that over 20 percent of the author entries have 'see' reference. Given that Lotka was dealing with over 6,000 entries it is no wonder he chose the shortcut. (p. 32)

Many of the studies using small sample sizes found that their results did not conform to Lotka's law. Many researchers (Huber \& Wagner-Dobler, 2001; Pao, 1985; Potter, 1981 believe that a large sample size is needed in order to reliably test Lotka's law. Huber and Wagner-Dobler (2001) states, “...it is important that the sample have about 1,000 authors or more, because most authors produce very few publications...." (p. 344). Lotka's own data sets consisted of 6,891 authors from Chemical Abstracts and 1,325 from Auerbach. 
It is recommended that the data collected be representative of publications during a timeframe of at least five years or more. Potter (1981) notes that looking at author productivity during a timeframe of 10 years or more produces a frequency distribution that closely resembles Lotka's law. Huber and Wagner-Dobler (2001) recommend that the sample cover a "long enough time interval such that many authors will have their complete careers recorded, at least for the field of interest" (p. 323).

The breadth and scope of the source is also important. Lotka chose the 10- year index for Chemical Abstracts and the Auerbach name index, which covered the entire history of physics up to 1900 . These sources offered sufficient representation of publications produced by an author during his professional lifetime and in the latter case, perhaps his or her entire lifetime. There have been a number of single journal-based studies in library and information studies testing Lotka's law (Cline, 1982; Nisonger, 1996; Potter, 1981), which have resulted in misleading and non-generalizable results. Joswick (1999) comments on these journal-based studies saying, "Although library literature contains a significant number of journal-based studies, individual-based studies are rarer and often focus on narrow segments of the library population" (p. 340). The most appropriate method by which to test Lotka's law would involve individual-based data, following Lotka's own example. This study has done exactly that.

Typically research studies testing Lotka's law have used $n=2$ (Budd \& Seavey, 1990; Murphy, 1973; Schorr, 1974) as the value of the exponent (which may have resulted in Lotka's law commonly being referred to as an inverse 'square' law) when calculating the value of $C$. While Lotka did present and discuss his formula in simpler 
terms using the value $n=2$, it should not be overlooked that he calculated the value of $n$ (and $C$ ) for each data set studied. Therefore, rather than referring to Lotka's law as the inverse 'square' law it would be more appropriate to refer to it as an inverse 'power' law, since the value of $n$ is calculated for each data set tested and its value is not always equal to 2, as found in this study and a number of others (Nicholls, 1987; Pao, 1985; Patra \& Mishra, 2006; Rai, 2005). Kretschmer and Rousseau (2001) underscore the importance of calculating these values for each data set by stating, "It is well known that the exponent $\propto$ is not a constant across databases. It changes with the age of the field.... and is probably also field dependent" (p. 610).

All of these factors were taken into account in the current study when following Pao's (1985) recommendations. The Pao - Lotka procedures were implemented leading to the following finding: Lotka's law can be used to predict author publication productivity in library and information studies with reliable results.

\section{Summary}

The values of $n$ and $C$ for this data set are -2.1 and 0.6418 respectively. The results of the K-S goodness-of-fit test indicate that Lotka's law can be used as a valid means of predicting author productivity in the field of library and information studies. In contrast to earlier studies in the field, (Budd \& Seavey, 1990; Cline, 1982; Coile, 1977; Murphy, 1973; Schorr, 1974) this study found that Lotka's law is indeed applicable to library and information studies and reliably so. This in part, is due to the fact that the study closely followed the procedures outlined by Pao (1985), which mirrored that of 
Lotka's original 1926 study more so than any of the previous studies conducted in LIS or other disciplines and fields. 


\section{CHAPTER V}

\section{CONCLUSIONS AND RECOMMENDATIONS}

Many researchers (Budd, 1981; Budd \& Seavey, 1996; Nicholls, 1987; Pao, 1985;

Potter, 1981) have lamented that the studies of author publication productivity in Library

and Information Studies have used varying methods. Budd and Seavey (1996) comment:

The last decade or so has produced a number of studies attempting to measure research and publishing productivity in library and information science... While the studies conducted so far are not directly comparable with one another due to the difference of focus, scope, and methodology, together they present information about some important aspects of the basic issue of structure of the literature in this field. (p. 2)

The procedural variations in the studies testing Lotka's law have led to anecdotal evidence at best and results that cannot be compared across studies.

\section{Conclusions}

This study has responded to the needs expressed by many scholars in the field (Budd \& Seavey, 1990, 1996; Liu, 2003; Nicholls, 1989; Wiberley, Hurd \& Weller, 2006) for a reliable method by which to measure author publication productivity. The applicability of Lotka's law to LIS literature offers the profession just that; an analytical tool that has been statistically proven as a reliable method of measuring author productivity. Lotka's law provides academic librarians with the capability to establish benchmarks for publication productivity in a way that can be compared within and across organizations, as well as, fields and disciplines. By employing Lotka's law, the profession can establish mathematically proven thresholds or benchmarks for publication expectations for library faculty in academia (and collegiate faculty at large); raise the level of visibility and credibility of scholars in the field; inform policy regarding the 
appointment, tenure and promotion process in higher education; and lastly, this measure of publication activity will provide a foundation for further studies researching author characteristics (e.g., gender, geographic location, rank and status, etc.) and research trends for best practices with publication efforts.

Although the exact figures of the number of institutions requiring publication by faculty libraries for tenure and promotion vary among the studies cited in LIS literature, researchers tend agree that tenure and promotion process for academic librarians has been a major impetus in the publication productivity of library scholars along with the desire for recognition by their peers (Budd \& Seavey, 1990, 1996; Cline, 1982; Hart, 2000; Joswick, 1999; Liu, 2003; Park \& Riggs, 1991; Potter, 1981; Wilberly, Hurd \& Weller, 2006; Weller, Hurd \& Wiberley, 1991; Zemon \& Bahr, 1998). There is no doubt that the high producers in this study fall into one or both of these categories.

The process of tenure and promotion is only applicable to faculty librarians on the tenure track and there are few exceptions to the publication requirements. Park and Riggs (1991) assert, "When academic librarians apply for tenure or promotion, they are judged as faculty, not as librarians...” (p. 276). Unfortunately, the fact that library faculty and teaching faculty perform very different job functions is not taken into consideration, not even by the national library organization that represents the best interest of its membership. The benefits (i.e., sabbaticals, reassign time, etc.) provided to teaching faculty to assist them with their research and publishing efforts are not necessarily shared by their library faculty counterparts. Park and Riggs (1991) observe,

Even with faculty status, academic librarians do not necessarily have the same rights and privileges as teaching faculty. Librarians are rarely paid on the same 
scale; they may not be eligible for tenure and promotion through the academic ranks, or for sabbatical leave and research funds; and they routinely work 35 to 40 hours per week with 12- rather than 9-month contracts. (p. 276).

From the administrative point of view, the results of this study should be disturbing. It indicates that librarians average about 1.7 articles. This data alone should be enough to justify the need for equal benefits that are already provided to their teaching faculty counterparts, to aid library faculty in their research efforts.

The establishment of publication productivity benchmarks based on Lotka's law can alleviate this inequity. As an example, this study has shown (see Table 4) that about $58 \%$ of authors in the field produce at least one article. Roughly $80 \%$ of all authors publish between one and three articles leaving $20 \%$ who publish four or more articles. Therefore tenure and promotion policies for library faculty requiring between one and four publications are appropriate and more realistic. The more outstanding authors in the field would produce at least four or more publications.

Lotka's law can be used to identify and implement publication productivity benchmarks for each discipline or department existing within a college or university. By doing so, university and college administrators will have achieved a standardized way of accounting for publication productivity among homogeneous populations providing a more realistic and appropriate measure of productivity expectations of their faculty. Using benchmarks determined by Lotka's law to establish thresholds for publication activity to guide budgetary decisions is yet another way to equitably reward departments or faculty for their scholarly efforts. 
In addition to aiding in the tenure and promotion process, author publication productivity is also reflective of the author's organization. Budd (2006) notes, "Rankings by the U.S. News \& World Report, the National Research Council and others frequently include metrics that account for numbers of publications, among other variables. In short, more publications can lead to higher rankings of academic programs and entire institutions" (p. 230). Most recently (December 2007) Academic Analytics ranked Florida International University's Ph.D. faculty of the social welfare department as number four in the nation for their scholarly accomplishments. Academic Analytics produces the Faculty Scholarly Productivity (FSP) Index, which includes factors rankings such as the number of books published and journal publications. Thus proving that recognition for a faculty who produces scholarship is generally given on an institutional level. Surely this recognition will help FIU's department of social welfare during the next budgeting process as the university will reward in some fashion, the department that has brought it such good publicity.

Academic librarians should take advantage of opportunities to highlight their scholarly contributions not only to their profession but also to the field of higher education. Lotka's law provides librarians with another means of quantifying contributions not only in their primary profession, but in their secondary profession as well. Although the library as a department is considered part of the academic fabric of an institution, library faculty are not immediately perceived as equals among faculty scholars. Although referred to as "the gatekeepers of knowledge", ironically librarians are not known for generating primary research data, but are better known for their ability to find such data. Crawford (1999) states, "Whenever the literature of library and 
information studies is discussed, one often hears that the field lacks a good research base...” (p. 224).

The implementation of a reliable method for determining an average number of publications produced by library faculty based on the publication productivity for the field and perhaps even their particular subject specialty is vital. Wiberley, Hurd, and Weller (2006) state,

To compete in the marketplace of disciplines, relatively small and comparatively young fields such as LIS need knowledge of themselves and of their standards more than do older fields such as chemistry and history that the general public, as well as academics understand better. (p. 25)

Using Lotka's law to illustrate and predict author publication productivity can provide library and information studies scholars with a means of fair comparison with their teaching faculty colleagues within their institutions of higher learning. Morris and Goldstein (2007) write, "The productivity of authors measured in the number of articles they publish, is an indicator of their standing and importance in the specialty" (p. 1764). In addition, Buttlar (1991) asserts, "The proliferation of library literature is evidence of the growing maturity of librarianship" (p. 39). Wiberley, Hurd, and Weller (2006) follow suit, noting that the number of articles, "also are a measure of the health and strength of LIS" (p. 215).

\section{Recommendations}

Having a standardized measure for determining author productivity in LIS, provides a departure point for additional avenues of studies. Budd and Seavey (1990) acknowledge, 
This phenomenon, which has come to be referred to as Lotka's law is not intended as an explanation of why some authors are more prolific than others. Because of varying modes of behavior, patterns of productivity will differ among disciplines (p. 465).

As has been previously noted, the major drawback to previous studies of author publication productivity is that they used varying methods; therefore, their results are not comparable across studies. Using Lotka's law as a departure point allows for some standardization of the procedures used for studies of author publication productivity while allowing researchers to address additional impacting factors. For example, one can examine the characteristics of the more prolific authors in the resulting frequency distribution to discern trends such as gender, geographic location, institution type, etc. The distribution range could also be segmented into tiers (e.g., low, medium, high) and researchers can attempt to discern like characteristics of groups of authors who tend to fall into each tier. Since they would have followed the same basic procedure to achieve the frequency distribution, the studies would be comparable on some level.

While this study indicates that the data set studied does conform to Lotka's law, it represents only a subset of all the literature in the area of study from select journals indexed in ISI WOK. Further studies using sources such as Library Literature and Information Science (LLIS), Library Information Science \& Technology Abstracts (LISTA), or LISA: Library and Information Science Abstracts, which cover a longer period (mid-1960's to present) are international in scope and index over $400+$ periodicals are recommended. LISTA may well be the best choice of the three since it is international in scope indexes over $600+$ publications including research reports, books, and conference proceedings. However, there are a couple of challenges with using any above 
the above data sources: (a) the search algorithms and (b) the inability to download and import the citation results into Excel or like program.

If one were to take a systematic approach to attributing author credit (i.e., searching authors alphabetically) the search algorithms for these databases return all citations that have names beginning with the letter searched in the author field, regardless of whether it appears first or last in the author field. Therefore, the researcher will have to spend time sorting through all results to account for lead authors for each letter of the alphabet searched.

The convenience of being able to import result citations into Excel is what is appealing about using ISI WOK for citation analysis studies; however, even before this functionality was available ISI provided the most facile and efficient means of conducting citation analysis and was the tool of choice for such studies. Unfortunately, LLIS, LISA and LISTA were not built for this same purpose, but rather as a means of organizing and providing access points to various publications in the LIS field. Therefore, when using these products the researcher, like Lotka, will have to record each count manually, since these databases do not have the functionality allowing easy downloading and importing of citation results. Thus resulting in a most time consuming process.

Faculty members in the schools of Library and Information Studies have been the focus of a few studies in the recent past looking at publication productivity (Budd, 1999; Budd \& Seavey, 1996; Hayes, 1983; Terry, 1996; Watson, 1985). This population of LIS professionals has the primary responsibility of teaching and training new librarians, but as academicians they are also held to the standards of tenure and promotion that require 
research and publication. With the dwindling number of library schools, the studentconsumer has limited choices for graduate studies, especially in certain geographic areas. Future publication productivity studies of LIS faculty will help provide graduate school consumers with some indication of the quality of the faculty and program at any institution of interest. The scholarship of library faculty will have a positive impact on the prestige of the program as well as the prestige of the parent institution. In addition to studies focusing on LIS education faculty, researchers should also look at specialty areas within the LIS field which are well represented in the LIS schools, such as school librarianship and public librarianship.

As with other studies looking at author publication productivity, this study can be expanded upon by taking a closer look at the characteristics of the most and the least prolific authors. Notably only one of the five most productive authors in this study has published within the last two years. Worthy of additional note is that three of the four have numerous publications in the same journal, Notes. This observation lends itself to further research concerning the types of publications submitted (i.e., book reviews, editorial material, brief communications, etc.), but since it is out of the scope of this study a recommendation for further study focusing on this aspect is encouraged.

Although the more instinctive approach is to focus on the high producers, but there is just as much to be learned from those who have only produced one publication. Focusing on characteristics, such as institution type, gender, topics, subject areas covered, and rank and status are but a few characteristics that could be addressed in such studies. Many of these same characteristics have been addressed by previous researchers 
(Bonnevie, 2003; Budd \& Seavey, 1996; Cline, 1982; Hart, 2000; Potter, 1981; Terry, 1996; Watson, 1985; Wiberley, Hurd \& Weller, 2006) however, because of the varying methods employed their results are neither comparable nor generalizable and additional studies are warranted. Additional factors that could be addressed for those with single contributions include motivational factors, barriers to research and publication, and a comparison of institutional tenure and promotion policies.

What has not been addressed in the published literature is a detailed study of institutional policies concerning publication productivity and its impact on the appointment, tenure and promotion process of academic librarians. Currently only the largest research libraries have been surveyed for such data with surprising results: the number of research libraries that expect library faculty to publish is much lower than expected. A study of the tenure and promotion policies of various institution types (i.e., public, private, Carnegie classification, historically black colleges and universities, traditionally white institutions, etc.) would be extremely revealing to academic librarians and to their administrators when considering how to address research leave, establish realistic publication goals, and creating support services or programs that would benefit library faculty in the tenure and promotion process. Along this same vein, such studies can also serve to collect trend data on publication productivity, which is not typically required of librarians for institutional accreditation purposes.

How to best account for collaborative publications has become of increasing interest as more and more publications in LIS and other disciplines are products of a collaborative effort. Lotka's (1926) study only credited leading authors in his study and 
omitted corporate authors, since the latter authors tend to work in groups. There is a growing dissatisfaction with his method since it does not provide an accurate account of an author's total productivity. A few researchers (Hart, 2000; Nicholls, 1987; Terry, 1986) have grappled with how to account for collaborative authorship when applying Lotka's law and have unsuccessfully employed any one of the following three methods: (a) crediting the lead author, (b) using fractional attribution to give partial credit to each collaborative author, and (c) giving each collaborating author full credit. Although academic librarians continue to publish single-authored works, the growing number of collaborative authorship in the field warrant further study to determine the most viable means of considering collaborative authorship when applying Lotka's law.

The results of this study provide a common approach to researching author publication productivity that should be explored further. As new and enhanced Internet technologies such as Google, Web tools such as blogs, wikis and electronic journals offer faculty new means of publishing, traditional citation analysis tools such as ISI citation databases are becoming less effective and accurate tools of measurement. Meho \& Yang (2007) note that until recently, WoS (Web of Science) was the standard tool for conducting citation analysis studies; however, there are currently over 100 databases or tools that can be used for extensive citation searching and bibliometric analysis in addition to ISI WOK such as Scopus and Google Scholar. As members of a profession that has traditionally tackled and harnessed emerging technologies in order to provide library users with the most efficient means of access to information, librarians now need to use this ability and employ new technologies and research methodologies to quantify 
and demonstrate their individual contributions to the growing body of scholarship in the fields of library and information studies and higher education. 


\section{REFERENCES}

Association of College and Research Libraries (2007). A Guideline for the Appointment, Promotion and Tenure of Academic Librarians. Retrieved January 3, 2008, from http://www.ala.org/ala/acrl/acrlstandards/promotiontenure.cfm

Baker, J., Robertson-Wilson, J., \& Sedgwick, W. (2003). Publishing productivity in sport psychology 1970-2000: An exploratory examination of the Lotka-Price Law. Journal of Sport \& Exercise Psychology, 25, 477-483.

Black, T. R. (2003). Doing Quantitative research in the Social Sciences: An integrated approach to research design and statistics. Thousand Oaks, CA: SAGE Publications.

Bonnevie, E. (2003). A multifaceted portrait of library and information science journal: The case of the Journal of Information Science. Journal of Information Science, 29, 11-23.

Budd, J. M. (1999). Increases in faculty publishing activity: An analysis of ARL and ACRL institutions. College \& Research Libraries, 60, 308-315.

Budd, J. M. (2006). Faculty publishing productivity: Comparisons over time. College \& Research Libraries, 67, 230-239.

Budd, J. M., \& Seavey, C. A. (1990). Characteristics of journal authorship by academic librarians. College \& Research Libraries, 51, 463-470.

Buttlar, L. (1991). Analyzing the library periodical literature: Content and authorship. College \& Research Libraries, 41, 38-53.

Cline, G. S. (1982). College \& research libraries: Its first forty years. College \& Research Libraries, 43, 208-232.

Coile, R. C. (1977). Lotka's frequency distribution of scientific productivity. Journal of the American Society for Information Science, 28, 366-370.

Crawford, G. A. (1999). The research literature of academic librarianship: A comparison of college and research libraries and journal of academic librarianship. College \& Research Libraries, 65, 224-230.

Egghe, L. (2005). Power laws in the information production process: Lotkaian informetrics. New York: Elsevier/Academic Press.

Fang, P. H. \& Fang, J. M. (1995). A modification of Lotka's function for scientific productivity. Information Processing \& Management, 31, 133-137. 
Florida International University, University Media Relations. "Raising the Bar of Excellence." Florida International University, University Advancement Media Relations, January 3, 2008. http://news.fiu.edu/releases/2007/1221_excellence.htm. Accessed January 3, 2008.

Gross, P. L. K., \& Gross, E. M. (1927). College libraries and chemical education. Science, 66, 385-389.

Gupta, B. M., \& Karisiddippa, C. R. (1999). Collaboration and author productivity: A study with a new variable in Lotka's law. Scientometrics, 44, 129-134.

Hakanson, M. (2005). The impact of gender on citations: An analysis of college \& research libraries, journal of academic librarianship, and library quarterly. College \& Research Libraries, 66, 312-322.

Hart, R. (2000). Collaborative publication by university librarians: An exploratory study. The Journal of Academic Librarianship, 26, 94-99.

Henry, D. B., \& Neville, T. M. (2004). Research, publication, and service patterns of Florida academic librarians. The Journal of Academic Librarianship, 30, 435-451.

Huber, J. C., \& Wagner-Dobler, R. (2001). Scientific production: A statistical analysis of authors in mathematical logic. Scientometrics, 50, 323-337.

Joswick, K. E. (1999). Article publications patterns of academic librarians: An Illinois case study. College \& Research Libraries, 60, 340-349.

Krausse, S. C., \& Sieburth, J. F. (1985). Patterns of authorship in library journals by academic librarians. The Serials Librarian, 9, 127-138.

Lotka, A. J. (1926). The frequency distribution of scientific productivity. Journal of the Washington Academy of Sciences, 16, 317-323.

Loughner, W. (1992). Lotka's law and the kolmogorov-smirnov test: An error in calculation. Journal of the American Society for Information Science, 43, 149150.

MacRoberts, M. H., \& MacRoberts, B. R. (1982). A re-evaluation of Lotka's law of scientific productivity. Social Studies of Science, 12, 443-450.

Morris, S. A., \& Goldstein, M. L. (2007). Manifestation of research teams in journal literature: A growth model of papers, authors, collaboration, coauthorship, weak ties, and Lotka's law. Journal of the American Society for Information Science \& Technology, 58, 1764-1782. 
Murphy, L. J. (1973). Lotka's law in the humanities. Journal of the American Society for Information Science, 24, 461-462.

Nicholls, P. T. (1986). Empirical validation of Lotka's law. Information Processing \& Management, 22, 417-419.

Nicholls, P. T. (1989). Bibliometric modeling processes and the empirical validity of Lotka's law. Journal of the American Society for Information Science, 40, 379385.

Nisonger, T. E. (1996). Authorship in library acquisitions: Practice \& theory. Library Acquisitions: Practice \& Theory, 20, 395-419.

Nisonger, T. E. (2004). Citation autobiography: An investigation of ISI database coverage in determining author citedness. College \& Research Libraries, 65, 152163.

Nisonger, T. E., \& Davis, C. H. (2005). The perception of library and Information science journals by LIS education deans and ARL library directors: A replication of the Kohl-Davis study. College \& Research Libraries, 66, 341-377.

Pao, M. L. (1985). Lotka's law: A testing procedure. Information Processing \& Management, 21, 305-320.

Pao, M. L. (1986). An empirical examination of Lotka's law. Journal of the American Society for Information Science, 37, 26-33.

Park, B., \& Riggs, R. (1991). Status of the profession: A 1989 national survey of tenure and promotion policies for academic librarians. College \& Research Libraries, $52,275-289$.

Patra, S. K., Bhattacharya, P., \& Verma, N. (2006). Bibliometric study of literature on bibliometrics. DESIDOC Bulletin of Information Technology, 26, 27-32.

Patra, S. K., \& Chand, P. (2006). Library and information science research in India: A bibliometric study. Annals of Library and Information Studies, 53, 219-223.

Patra, S. K., \& Mishra, S. (2006). Bibliometric study of bioinformatics literature. Scientometrics, 67, 477-489.

Potter, W. (1981). Lotka's law revisited. Library Trends, 30, 21-39.

Price, D. S. (1961). Science since Babylon. New Haven, CT: Yale University Press. 
Price, D. S. (1963). Little science, big science. New York: Columbia University Press.

Price, D. S. (1976). A general theory of bibliometric and other cumulative advantage processes. Journal of the American Society for Information Science, 27, 292-306.

Pritchard, A. (1969). Statistical bibliography or bibliometrics? Journal of Documentation, 25, 348-349.

Rai, L. P., \& Kumar, N. (2005). A rationale for Lotka's law: An examination of empirical data. Annals of Library and Information Studies, 52, 103-107.

Saam, N. J., \& Reiter, L. (1999). Lotka's law reconsidered: The evolution of publication and citation distributions in scientific fields. Scientometrics, 44, 135-155.

Schorr, A. E. (1974). Lotka's law and library science. Research Quarterly, 14, 32-33.

Teodorescu, D. (2000). Correlates of faculty publication productivity: A cross-national analysis. Higher Education, 39, 201-222.

Terry, J. L. (1996). Authorship in college \& Research Libraries revisited: Gender, institutional affiliation, collaboration. College \& Research Libraries, 57, 377-383.

Watson, P. D. (1985). Production of scholarly articles by academic librarians and library school faculty. College \& Research Libraries, 46, 334-342.

Weller, A. C., Hurd, J. M., \& Wiberley, Stephen E. Jr. (1999). Publication patterns of U.S. academic librarians from 1993 to 1997. College \& Research Libraries, 60, 352-362.

Wiberley, S. E., Hurd, J. M., \& Weller, A. C. (2006). Publication patterns of U.S. academic librarians from 1998 to 2002. College \& Research Libraries, 67, 205216.

Zemon, M., \& Bahr, A. H. (1998). An analysis of articles by college librarians. College \& Research Libraries, 59, 421-431. 


\section{APPENDIX A}

Percent of Total

Observed

\begin{tabular}{|c|c|c|c|c|c|c|}
\hline $\begin{array}{c}\text { Number of } \\
\text { Contributions }\end{array}$ & Letter A & Letter B & $A+B$ & A & B & $A+B$ \\
\hline Total & 610 & 1,246 & 1856 & & & \\
\hline 1 & 391 & 836 & 1227 & $64.10 \%$ & $67.09 \%$ & $66.11 \%$ \\
\hline 2 & 84 & 234 & 318 & $13.77 \%$ & $18.78 \%$ & $17.13 \%$ \\
\hline 3 & 46 & 109 & 155 & $7.54 \%$ & $8.75 \%$ & $8.35 \%$ \\
\hline 4 & 28 & 160 & 188 & $4.59 \%$ & $12.84 \%$ & $10.13 \%$ \\
\hline 5 & 18 & 50 & 68 & $2.95 \%$ & $4.01 \%$ & $3.66 \%$ \\
\hline 6 & 4 & 26 & 30 & $0.66 \%$ & $2.09 \%$ & $1.62 \%$ \\
\hline 7 & 9 & 12 & 21 & $1.48 \%$ & $0.96 \%$ & $1.13 \%$ \\
\hline 8 & 5 & 10 & 15 & $0.82 \%$ & $0.80 \%$ & $0.81 \%$ \\
\hline 9 & 6 & 13 & 19 & $0.98 \%$ & $1.04 \%$ & $1.02 \%$ \\
\hline 10 & 5 & 12 & 17 & $0.82 \%$ & $0.96 \%$ & $0.92 \%$ \\
\hline 11 & 1 & 8 & 9 & $0.16 \%$ & $0.64 \%$ & $0.48 \%$ \\
\hline 12 & 2 & 7 & 9 & $0.33 \%$ & $0.56 \%$ & $0.48 \%$ \\
\hline 13 & 0 & 9 & 9 & $0.00 \%$ & $0.72 \%$ & $0.48 \%$ \\
\hline 14 & 0 & 6 & 6 & $0.00 \%$ & $0.48 \%$ & $0.32 \%$ \\
\hline 15 & 1 & 2 & 3 & $0.16 \%$ & $0.16 \%$ & $0.16 \%$ \\
\hline 16 & 0 & 5 & 5 & $0.00 \%$ & $0.40 \%$ & $0.27 \%$ \\
\hline 17 & 2 & 6 & 8 & $0.33 \%$ & $0.48 \%$ & $0.43 \%$ \\
\hline 18 & 1 & 1 & 2 & $0.16 \%$ & $0.08 \%$ & $0.11 \%$ \\
\hline 19 & 0 & 0 & 0 & $0.00 \%$ & $0.00 \%$ & $0.00 \%$ \\
\hline 20 & 1 & 3 & 4 & $0.16 \%$ & $0.24 \%$ & $0.22 \%$ \\
\hline 21 & 0 & 1 & 1 & $0.00 \%$ & $0.08 \%$ & $0.05 \%$ \\
\hline 22 & 2 & 2 & 4 & $0.33 \%$ & $0.16 \%$ & $0.22 \%$ \\
\hline 23 & 1 & 1 & 2 & $0.16 \%$ & $0.08 \%$ & $0.11 \%$ \\
\hline 24 & 0 & 3 & 3 & $0.00 \%$ & $0.24 \%$ & $0.16 \%$ \\
\hline 25 & 1 & 0 & 1 & $0.16 \%$ & $0.00 \%$ & $0.05 \%$ \\
\hline 26 & 0 & 0 & 0 & $0.00 \%$ & $0.00 \%$ & $0.00 \%$ \\
\hline 27 & 0 & 0 & 0 & $0.00 \%$ & $0.00 \%$ & $0.00 \%$ \\
\hline 28 & 0 & 1 & 1 & $0.00 \%$ & $0.08 \%$ & $0.05 \%$ \\
\hline 29 & 0 & 1 & 1 & $0.00 \%$ & $0.08 \%$ & $0.05 \%$ \\
\hline 30 & 0 & 1 & 1 & $0.00 \%$ & $0.08 \%$ & $0.05 \%$ \\
\hline 31 & 0 & 0 & 0 & $0.00 \%$ & $0.00 \%$ & $0.00 \%$ \\
\hline 32 & 0 & 0 & 0 & $0.00 \%$ & $0.00 \%$ & $0.00 \%$ \\
\hline 33 & 0 & 0 & 0 & $0.00 \%$ & $0.00 \%$ & $0.00 \%$ \\
\hline 34 & 0 & 1 & 1 & $0.00 \%$ & $0.08 \%$ & $0.05 \%$ \\
\hline 35 & 0 & 1 & 1 & $0.00 \%$ & $0.08 \%$ & $0.05 \%$ \\
\hline 36 & 0 & 0 & 0 & $0.00 \%$ & $0.00 \%$ & $0.00 \%$ \\
\hline 37 & 0 & 1 & 1 & $0.00 \%$ & $0.08 \%$ & $0.05 \%$ \\
\hline 38 & 0 & 0 & 0 & $0.00 \%$ & $0.00 \%$ & $0.00 \%$ \\
\hline 39 & 0 & 0 & 0 & $0.00 \%$ & $0.00 \%$ & $0.00 \%$ \\
\hline 40 & 0 & 0 & 0 & $0.00 \%$ & $0.00 \%$ & $0.00 \%$ \\
\hline 41 & 0 & 0 & 0 & $0.00 \%$ & $0.00 \%$ & $0.00 \%$ \\
\hline
\end{tabular}


Percent of Total

Observed

\begin{tabular}{|c|c|c|c|c|c|c|}
\hline $\begin{array}{c}\text { Number of } \\
\text { Contributions }\end{array}$ & Letter A & Letter B & $A+B$ & $\mathrm{~A}$ & $\mathrm{~B}$ & $A+B$ \\
\hline 42 & 0 & 0 & 0 & $0.00 \%$ & $0.00 \%$ & $0.00 \%$ \\
\hline 43 & 0 & 0 & 0 & $0.00 \%$ & $0.00 \%$ & $0.00 \%$ \\
\hline 44 & 0 & 1 & 1 & $0.00 \%$ & $0.08 \%$ & $0.05 \%$ \\
\hline 45 & 0 & 0 & 0 & $0.00 \%$ & $0.00 \%$ & $0.00 \%$ \\
\hline 46 & 0 & 0 & 0 & $0.00 \%$ & $0.00 \%$ & $0.00 \%$ \\
\hline 47 & 0 & 0 & 0 & $0.00 \%$ & $0.00 \%$ & $0.00 \%$ \\
\hline 48 & 0 & 0 & 0 & $0.00 \%$ & $0.00 \%$ & $0.00 \%$ \\
\hline 49 & 0 & 0 & 0 & $0.00 \%$ & $0.00 \%$ & $0.00 \%$ \\
\hline 50 & 0 & 0 & 0 & $0.00 \%$ & $0.00 \%$ & $0.00 \%$ \\
\hline 51 & 0 & 0 & 0 & $0.00 \%$ & $0.00 \%$ & $0.00 \%$ \\
\hline 52 & 0 & 0 & 0 & $0.00 \%$ & $0.00 \%$ & $0.00 \%$ \\
\hline 53 & 0 & 0 & 0 & $0.00 \%$ & $0.00 \%$ & $0.00 \%$ \\
\hline 54 & 0 & 0 & 0 & $0.00 \%$ & $0.00 \%$ & $0.00 \%$ \\
\hline 55 & 0 & 0 & 0 & $0.00 \%$ & $0.00 \%$ & $0.00 \%$ \\
\hline 56 & 1 & 0 & 1 & $0.16 \%$ & $0.00 \%$ & $0.05 \%$ \\
\hline 57 & 0 & 0 & 0 & $0.00 \%$ & $0.00 \%$ & $0.00 \%$ \\
\hline 58 & 0 & 0 & 0 & $0.00 \%$ & $0.00 \%$ & $0.00 \%$ \\
\hline 59 & 0 & 0 & 0 & $0.00 \%$ & $0.00 \%$ & $0.00 \%$ \\
\hline 60 & 0 & 0 & 0 & $0.00 \%$ & $0.00 \%$ & $0.00 \%$ \\
\hline 61 & 0 & 1 & 1 & $0.00 \%$ & $0.08 \%$ & $0.05 \%$ \\
\hline 66 & 0 & 1 & 1 & $0.00 \%$ & $0.08 \%$ & $0.05 \%$ \\
\hline 67 & 0 & 0 & 0 & $0.00 \%$ & $0.00 \%$ & $0.00 \%$ \\
\hline 68 & 0 & 0 & 0 & $0.00 \%$ & $0.00 \%$ & $0.00 \%$ \\
\hline 69 & 0 & 0 & 0 & $0.00 \%$ & $0.00 \%$ & $0.00 \%$ \\
\hline 70 & 0 & 0 & 0 & $0.00 \%$ & $0.00 \%$ & $0.00 \%$ \\
\hline 71 & 0 & 0 & 0 & $0.00 \%$ & $0.00 \%$ & $0.00 \%$ \\
\hline 72 & 0 & 0 & 0 & $0.00 \%$ & $0.00 \%$ & $0.00 \%$ \\
\hline 73 & 0 & 0 & 0 & $0.00 \%$ & $0.00 \%$ & $0.00 \%$ \\
\hline 74 & 0 & 0 & 0 & $0.00 \%$ & $0.00 \%$ & $0.00 \%$ \\
\hline 75 & 0 & 0 & 0 & $0.00 \%$ & $0.00 \%$ & $0.00 \%$ \\
\hline 76 & 0 & 0 & 0 & $0.00 \%$ & $0.00 \%$ & $0.00 \%$ \\
\hline 77 & 0 & 0 & 0 & $0.00 \%$ & $0.00 \%$ & $0.00 \%$ \\
\hline 78 & 0 & 0 & 0 & $0.00 \%$ & $0.00 \%$ & $0.00 \%$ \\
\hline 79 & 0 & 0 & 0 & $0.00 \%$ & $0.00 \%$ & $0.00 \%$ \\
\hline 80 & 0 & 0 & 0 & $0.00 \%$ & $0.00 \%$ & $0.00 \%$ \\
\hline 81 & 0 & 0 & 0 & $0.00 \%$ & $0.00 \%$ & $0.00 \%$ \\
\hline 82 & 0 & 0 & 0 & $0.00 \%$ & $0.00 \%$ & $0.00 \%$ \\
\hline 83 & 0 & 0 & 0 & $0.00 \%$ & $0.00 \%$ & $0.00 \%$ \\
\hline 84 & 0 & 0 & 0 & $0.00 \%$ & $0.00 \%$ & $0.00 \%$ \\
\hline 85 & 0 & 0 & 0 & $0.00 \%$ & $0.00 \%$ & $0.00 \%$ \\
\hline 86 & 0 & 0 & 0 & $0.00 \%$ & $0.00 \%$ & $0.00 \%$ \\
\hline 87 & 0 & 0 & 0 & $0.00 \%$ & $0.00 \%$ & $0.00 \%$ \\
\hline 88 & 0 & 0 & 0 & $0.00 \%$ & $0.00 \%$ & $0.00 \%$ \\
\hline 89 & 0 & 0 & 0 & $0.00 \%$ & $0.00 \%$ & $0.00 \%$ \\
\hline 90 & 0 & 0 & 0 & $0.00 \%$ & $0.00 \%$ & $0.00 \%$ \\
\hline
\end{tabular}


Percent of Total

Observed

\begin{tabular}{|c|c|c|c|c|c|c|}
\hline & & & & & & \\
\hline $\begin{array}{c}\text { Number of } \\
\text { Contributions }\end{array}$ & Letter A & Letter B & $A+B$ & A & B & $A+B$ \\
\hline 91 & 0 & 0 & 0 & $0.00 \%$ & $0.00 \%$ & $0.00 \%$ \\
\hline 92 & 0 & 0 & 0 & $0.00 \%$ & $0.00 \%$ & $0.00 \%$ \\
\hline 93 & 0 & 0 & 0 & $0.00 \%$ & $0.00 \%$ & $0.00 \%$ \\
\hline 94 & 0 & 0 & 0 & $0.00 \%$ & $0.00 \%$ & $0.00 \%$ \\
\hline 95 & 0 & 0 & 0 & $0.00 \%$ & $0.00 \%$ & $0.00 \%$ \\
\hline 96 & 0 & 0 & 0 & $0.00 \%$ & $0.00 \%$ & $0.00 \%$ \\
\hline 97 & 0 & 0 & 0 & $0.00 \%$ & $0.00 \%$ & $0.00 \%$ \\
\hline 98 & 0 & 0 & 0 & $0.00 \%$ & $0.00 \%$ & $0.00 \%$ \\
\hline 99 & 0 & 0 & 0 & $0.00 \%$ & $0.00 \%$ & $0.00 \%$ \\
\hline 100 & 0 & 0 & 0 & $0.00 \%$ & $0.00 \%$ & $0.00 \%$ \\
\hline 101 & 0 & 0 & 0 & $0.00 \%$ & $0.00 \%$ & $0.00 \%$ \\
\hline 102 & 0 & 0 & 0 & $0.00 \%$ & $0.00 \%$ & $0.00 \%$ \\
\hline 103 & 0 & 0 & 0 & $0.00 \%$ & $0.00 \%$ & $0.00 \%$ \\
\hline 104 & 0 & 1 & 1 & $0.00 \%$ & $0.08 \%$ & $0.05 \%$ \\
\hline 105 & 0 & 0 & 0 & $0.00 \%$ & $0.00 \%$ & $0.00 \%$ \\
\hline 106 & 0 & 0 & 0 & $0.00 \%$ & $0.00 \%$ & $0.00 \%$ \\
\hline 107 & 0 & 0 & 0 & $0.00 \%$ & $0.00 \%$ & $0.00 \%$ \\
\hline 108 & 0 & 0 & 0 & $0.00 \%$ & $0.00 \%$ & $0.00 \%$ \\
\hline 109 & 0 & 0 & 0 & $0.00 \%$ & $0.00 \%$ & $0.00 \%$ \\
\hline 110 & 0 & 0 & 0 & $0.00 \%$ & $0.00 \%$ & $0.00 \%$ \\
\hline 111 & 0 & 0 & 0 & $0.00 \%$ & $0.00 \%$ & $0.00 \%$ \\
\hline 112 & 0 & 0 & 0 & $0.00 \%$ & $0.00 \%$ & $0.00 \%$ \\
\hline 113 & 0 & 0 & 0 & $0.00 \%$ & $0.00 \%$ & $0.00 \%$ \\
\hline 114 & 0 & 0 & 0 & $0.00 \%$ & $0.00 \%$ & $0.00 \%$ \\
\hline 115 & 0 & 0 & 0 & $0.00 \%$ & $0.00 \%$ & $0.00 \%$ \\
\hline 116 & 0 & 0 & 0 & $0.00 \%$ & $0.00 \%$ & $0.00 \%$ \\
\hline 117 & 0 & 0 & 0 & $0.00 \%$ & $0.00 \%$ & $0.00 \%$ \\
\hline 118 & 0 & 0 & 0 & $0.00 \%$ & $0.00 \%$ & $0.00 \%$ \\
\hline 119 & 0 & 0 & 0 & $0.00 \%$ & $0.00 \%$ & $0.00 \%$ \\
\hline 120 & 0 & 0 & 0 & $0.00 \%$ & $0.00 \%$ & $0.00 \%$ \\
\hline 121 & 0 & 0 & 0 & $0.00 \%$ & $0.00 \%$ & $0.00 \%$ \\
\hline 122 & 1 & 0 & 1 & $0.16 \%$ & $0.00 \%$ & $0.05 \%$ \\
\hline
\end{tabular}




\section{APPENDIX B}

Calculation of $n$ for $N$ cases

\begin{tabular}{ccrrrr}
$N=10$ & \multicolumn{7}{c}{} & & & \\
\hline$x$ & 1227 & $X=\log x$ & $Y=\log y$ & $X Y$ & $X X$ \\
\hline 1 & 318 & 0.00000 & 3.08884 & 0.00000 & 0.00000 \\
2 & 155 & 0.30103 & 2.50243 & 0.75331 & 0.09062 \\
3 & 188 & 0.47712 & 2.19033 & 1.04505 & 0.22764 \\
4 & 68 & 0.60206 & 2.27416 & 1.36918 & 0.36248 \\
5 & 30 & 0.69897 & 1.83251 & 1.28087 & 0.48856 \\
6 & 21 & 0.77815 & 1.47712 & 1.14942 & 0.60552 \\
7 & 15 & 0.84510 & 1.32222 & 1.11740 & 0.71419 \\
8 & 19 & 0.90309 & 1.17609 & 1.06212 & 0.81557 \\
9 & 17 & 0.95424 & 1.27875 & 1.22024 & 0.91058 \\
10 & 2058 & 1.00000 & 1.23045 & 1.23045 & 1.00000 \\
\hline \multicolumn{7}{c}{6.55976} & 18.37290 & 10.22804 & 5.21516 \\
\hline
\end{tabular}

$n=1.23045$

\begin{tabular}{ccrrrr}
$N=11$ & \multicolumn{7}{c}{} & \\
\hline$x$ & $y$ & $X=\log x$ & $Y=\log y$ & $X Y$ & $X X$ \\
\hline 1 & 1227 & 0.00000 & 3.08884 & 0.00000 & 0.00000 \\
2 & 318 & 0.30103 & 2.50243 & 0.75331 & 0.09062 \\
3 & 155 & 0.47712 & 2.19033 & 1.04505 & 0.22764 \\
4 & 188 & 0.60206 & 2.27416 & 1.36918 & 0.36248 \\
5 & 68 & 0.69897 & 1.83251 & 1.28087 & 0.48856 \\
6 & 30 & 0.77815 & 1.47712 & 1.14942 & 0.60552 \\
7 & 21 & 0.84510 & 1.32222 & 1.11740 & 0.71419 \\
8 & 15 & 0.90309 & 1.17609 & 1.06212 & 0.81557 \\
9 & 19 & 0.95424 & 1.27875 & 1.22024 & 0.91058 \\
10 & 17 & 1.00000 & 1.23045 & 1.23045 & 1.00000 \\
11 & 9 & 1.04139 & 0.95424 & 0.99374 & 1.08450 \\
\hline \multicolumn{7}{c}{2067} & 7.60116 & 19.32715 & 11.22178 & 6.29966 \\
\hline
\end{tabular}

$n=0.99042$ 


\begin{tabular}{ccrrrr}
$N=12$ & \multicolumn{7}{c}{$X Y$} & $X X$ \\
\hline$x$ & $y$ & $X=\log x$ & $Y=\log y$ & $X Y$ & 0.00000 \\
1 & 1227 & 0.00000 & 3.08884 & 0.00000 & 0.09062 \\
2 & 318 & 0.30103 & 2.50243 & 0.75331 & 0.22764 \\
3 & 155 & 0.47712 & 2.19033 & 1.04505 & 0.36248 \\
4 & 188 & 0.60206 & 2.27416 & 1.36918 & 0.48856 \\
5 & 68 & 0.69897 & 1.83251 & 1.28087 & 0.60552 \\
6 & 30 & 0.77815 & 1.47712 & 1.14942 & 0.71419 \\
7 & 21 & 0.84510 & 1.32222 & 1.11740 & 0.81557 \\
8 & 15 & 0.90309 & 1.17609 & 1.06212 & 0.91058 \\
9 & 19 & 0.95424 & 1.27875 & 1.22024 & 1.00000 \\
10 & 17 & 1.00000 & 1.23045 & 1.23045 & 1.08450 \\
11 & 9 & 1.04139 & 0.95424 & 0.99374 & 1.16463 \\
12 & 9 & 1.07918 & 0.95424 & 1.02980 & 7.46429 \\
\hline
\end{tabular}

$n=0.75377$

\begin{tabular}{|c|c|c|c|c|c|}
\hline$x$ & $y$ & $X=\log x$ & $Y=\log y$ & $X Y$ & $X X$ \\
\hline 1 & 1227 & 0.00000 & 3.08884 & 0.00000 & 0.00000 \\
\hline 2 & 318 & 0.30103 & 2.50243 & 0.75331 & 0.09062 \\
\hline 3 & 155 & 0.47712 & 2.19033 & 1.04505 & 0.22764 \\
\hline 4 & 188 & 0.60206 & 2.27416 & 1.36918 & 0.36248 \\
\hline 5 & 68 & 0.69897 & 1.83251 & 1.28087 & 0.48856 \\
\hline 6 & 30 & 0.77815 & 1.47712 & 1.14942 & 0.60552 \\
\hline 7 & 21 & 0.84510 & 1.32222 & 1.11740 & 0.71419 \\
\hline 8 & 15 & 0.90309 & 1.17609 & 1.06212 & 0.81557 \\
\hline 9 & 19 & 0.95424 & 1.27875 & 1.22024 & 0.91058 \\
\hline 10 & 17 & 1.00000 & 1.23045 & 1.23045 & 1.00000 \\
\hline 11 & 9 & 1.04139 & 0.95424 & 0.99374 & 1.08450 \\
\hline 12 & 9 & 1.07918 & 0.95424 & 1.02980 & 1.16463 \\
\hline \multirow[t]{2}{*}{13} & 9 & 1.11394 & 0.95424 & 1.06297 & 1.24087 \\
\hline & 2085 & 9.79428 & 21.23563 & 13.31456 & 8.70516 \\
\hline
\end{tabular}

$n=0.52126$ 


\begin{tabular}{ccrrrr}
$N=14$ & \multicolumn{7}{c}{$X Y$} & $X X$ \\
\hline$x$ & $y$ & $X=\log x$ & $Y=\log y$ & \multicolumn{1}{c}{$X Y$} & \multicolumn{1}{c}{ y } \\
\hline 1 & 1227 & 0.00000 & 3.08884 & 0.00000 & 0.00000 \\
2 & 318 & 0.30103 & 2.50243 & 0.75331 & 0.09062 \\
3 & 155 & 0.47712 & 2.19033 & 1.04505 & 0.22764 \\
4 & 188 & 0.60206 & 2.27416 & 1.36918 & 0.36248 \\
5 & 68 & 0.69897 & 1.83251 & 1.28087 & 0.48856 \\
6 & 30 & 0.77815 & 1.47712 & 1.14942 & 0.60552 \\
7 & 21 & 0.84510 & 1.32222 & 1.11740 & 0.71419 \\
8 & 15 & 0.90309 & 1.17609 & 1.06212 & 0.81557 \\
9 & 19 & 0.95424 & 1.27875 & 1.22024 & 0.91058 \\
10 & 17 & 1.00000 & 1.23045 & 1.23045 & 1.00000 \\
11 & 9 & 1.04139 & 0.95424 & 0.99374 & 1.08450 \\
12 & 9 & 1.07918 & 0.95424 & 1.02980 & 1.16463 \\
13 & 9 & 1.11394 & 0.95424 & 1.06297 & 1.24087 \\
14 & 6 & 1.14613 & 0.77815 & 0.89186 & 1.31361 \\
\hline
\end{tabular}

$n=0.24529$

\begin{tabular}{ccrrrr}
$N=15$ & \multicolumn{7}{c}{$X Y$} & $X X$ \\
\hline$x$ & $y$ & $X=\log x$ & $Y=\log y$ & \multicolumn{1}{c}{$X Y$} & 0.00000 \\
1 & 1227 & 0.00000 & 3.08884 & 0.00000 & 0.09062 \\
2 & 318 & 0.30103 & 2.50243 & 0.75331 & 0.22764 \\
3 & 155 & 0.47712 & 2.19033 & 1.04505 & 0.36248 \\
4 & 188 & 0.60206 & 2.27416 & 1.36918 & 0.48856 \\
5 & 68 & 0.69897 & 1.83251 & 1.28087 & 0.60552 \\
6 & 30 & 0.77815 & 1.47712 & 1.14942 & 0.71419 \\
7 & 21 & 0.84510 & 1.32222 & 1.11740 & 0.81557 \\
8 & 15 & 0.90309 & 1.17609 & 1.06212 & 0.91058 \\
9 & 19 & 0.95424 & 1.27875 & 1.22024 & 1.00000 \\
10 & 17 & 1.00000 & 1.23045 & 1.23045 & 1.08450 \\
11 & 9 & 1.04139 & 0.95424 & 0.99374 & 1.16463 \\
12 & 9 & 1.07918 & 0.95424 & 1.02980 & 1.24087 \\
13 & 9 & 1.11394 & 0.95424 & 1.06297 & 1.31361 \\
14 & 6 & 1.14613 & 0.77815 & 0.89186 & 1.38319 \\
15 & 3 & 1.17609 & 0.47712 & 0.56114 & 11.40196 \\
\hline \multicolumn{7}{c}{2094} & 12.11650 & 22.49090 & 14.76756 &
\end{tabular}




\begin{tabular}{ccrrrr}
$N=16$ & \multicolumn{7}{c}{$X$} & \\
\hline$x$ & $y$ & $X=\log x$ & $Y=\log y$ & $X Y$ & $X X$ \\
\hline 1 & 1227 & 0.00000 & 3.08884 & 0.00000 & 0.00000 \\
2 & 318 & 0.30103 & 2.50243 & 0.75331 & 0.09062 \\
3 & 155 & 0.47712 & 2.19033 & 1.04505 & 0.22764 \\
4 & 188 & 0.60206 & 2.27416 & 1.36918 & 0.36248 \\
5 & 68 & 0.69897 & 1.83251 & 1.28087 & 0.48856 \\
6 & 30 & 0.77815 & 1.47712 & 1.14942 & 0.60552 \\
7 & 21 & 0.84510 & 1.32222 & 1.11740 & 0.71419 \\
8 & 15 & 0.90309 & 1.17609 & 1.06212 & 0.81557 \\
9 & 19 & 0.95424 & 1.27875 & 1.22024 & 0.91058 \\
10 & 17 & 1.00000 & 1.23045 & 1.23045 & 1.00000 \\
11 & 9 & 1.04139 & 0.95424 & 0.99374 & 1.08450 \\
12 & 9 & 1.07918 & 0.95424 & 1.02980 & 1.16463 \\
13 & 9 & 1.11394 & 0.95424 & 1.06297 & 1.24087 \\
14 & 6 & 1.14613 & 0.77815 & 0.89186 & 1.31361 \\
15 & 3 & 1.17609 & 0.47712 & 0.56114 & 1.38319 \\
16 & 5 & 1.20412 & 0.69897 & 0.84164 & 1.44990 \\
\hline \multicolumn{7}{c}{2099} & 13.32062 & 23.18987 & 15.60920 & 12.85187 \\
\hline
\end{tabular}

\begin{tabular}{rcrrrr}
$N=17$ & \multicolumn{7}{c}{} & & \\
\hline$x$ & 1227 & $X=\log x$ & $Y=\log y$ & $X Y$ & $X X$ \\
\hline 1 & 318 & 0.00000 & 3.08884 & 0.00000 & 0.00000 \\
2 & 155 & 0.30103 & 2.50243 & 0.75331 & 0.09062 \\
3 & 188 & 0.47712 & 2.19033 & 1.04505 & 0.22764 \\
4 & 68 & 0.60206 & 2.27416 & 1.36918 & 0.36248 \\
5 & 30 & 0.69897 & 1.83251 & 1.28087 & 0.48856 \\
6 & 21 & 0.77815 & 1.47712 & 1.14942 & 0.60552 \\
7 & 15 & 0.84510 & 1.32222 & 1.11740 & 0.71419 \\
8 & 19 & 0.90309 & 1.17609 & 1.06212 & 0.81557 \\
9 & 17 & 0.95424 & 1.27875 & 1.22024 & 0.91058 \\
10 & 9 & 1.00000 & 1.23045 & 1.23045 & 1.00000 \\
11 & 9 & 1.04139 & 0.95424 & 0.99374 & 1.08450 \\
12 & 9 & 1.07918 & 0.95424 & 1.02980 & 1.16463 \\
13 & 6 & 1.11394 & 0.95424 & 1.06297 & 1.24087 \\
14 & 3 & 1.14613 & 0.77815 & 0.89186 & 1.31361 \\
15 & 5 & 1.17609 & 0.47712 & 0.56114 & 1.38319 \\
16 & 8 & 1.20412 & 0.69897 & 0.84164 & 1.44990 \\
17 & & 1.23045 & 0.90309 & 1.11121 & 1.51400 \\
\hline
\end{tabular}

$n=-1.05889$ 


\section{APPENDIX C}

K-S Test with $n=2$

Observed

\#

Publications Authors

\begin{tabular}{ccccccc}
\hline \multicolumn{5}{c}{$f_{o}\left(y_{x}\right)=y_{x}$} & \multicolumn{3}{c}{$f_{\mathrm{e}}\left(\mathrm{y}_{\mathrm{x}}\right)=\mathrm{C}$} & & $\sum f_{\mathrm{o}}\left(\mathrm{y}_{\mathrm{x}}\right)-$ \\
$x$ & $y_{x}$ & $\sum y_{x}$ & $\sum f_{\mathrm{o}}\left(\mathrm{y}_{\mathrm{x}}\right)$ & $\left(1 / \mathrm{x}^{\mathrm{n}}\right)$ & $\sum f_{\mathrm{e}}\left(\mathrm{y}_{\mathrm{x}}\right)$ & $\sum f_{\mathrm{e}}\left(\mathrm{y}_{\mathrm{x}}\right)$ \\
\hline 1 & 1227 & 0.581792 & 0.581792 & 0.608900 & 0.608900 & -0.027108 \\
2 & 318 & 0.150782 & 0.732575 & 0.152225 & 0.761125 & -0.028550 \\
3 & 155 & 0.073495 & 0.806069 & 0.067656 & 0.828781 & -0.022711 \\
4 & 188 & 0.089142 & 0.895211 & 0.038056 & 0.866837 & 0.028374 \\
5 & 68 & 0.032243 & 0.927454 & 0.024356 & 0.891193 & 0.036261 \\
6 & 30 & 0.014225 & 0.941679 & 0.016914 & 0.908107 & 0.033572 \\
7 & 21 & 0.009957 & 0.951636 & 0.012427 & 0.920533 & 0.031103 \\
8 & 15 & 0.007112 & 0.958748 & 0.009514 & 0.930047 & 0.028701 \\
9 & 19 & 0.009009 & 0.967757 & 0.007517 & 0.937565 & 0.030193 \\
10 & 17 & 0.008061 & 0.975818 & 0.006089 & 0.943654 & 0.032164 \\
11 & 9 & 0.004267 & 0.980085 & 0.005032 & 0.948686 & 0.031400 \\
12 & 9 & 0.004267 & 0.984353 & 0.004228 & 0.952914 & 0.031438 \\
13 & 9 & 0.004267 & 0.988620 & 0.003603 & 0.956517 & 0.032103 \\
14 & 6 & 0.002845 & 0.991465 & 0.003107 & 0.959624 & 0.031841 \\
15 & 3 & 0.001422 & 0.992888 & 0.002706 & 0.962330 & 0.030558 \\
16 & 5 & 0.002371 & 0.995258 & 0.002379 & 0.964709 & 0.030550 \\
17 & 8 & 0.003793 & 0.999052 & 0.002107 & 0.966816 & 0.032236 \\
18 & 2 & 0.000948 & 1.000000 & 0.001879 & 0.968695 & 0.031305 \\
\hline & 2109 & & & & & \\
\hline
\end{tabular}

$D_{\max } 0.036261$

Critical Value $=1.22 / \sqrt{2109+1}$

Critical Value $=0.0265592$

Since the $D_{\max }>$ Critical Value $(0.036261>0.265592)$ we must reject the null hypothesis that there is no significant difference between the observed distribution and the distribution predicted by Lotka's law. 
VITA

CONSUELLA A. ASKEW

1989

B.A., English

Spelman College

Atlanta, Georgia

1991

M.L.S., Library and Information Studies University of North Carolina at Greensboro Greensboro, North Carolina

1994-1995

School Media Coordinator

Durham Public Schools

Durham, North Carolina

1996-1997

Curriculum Materials Center Librarian Shepard Library

North Carolina Central University

Durham, North Carolina

Adjunct Instructor

School of Education

$1997-2000$

Bibliographic Instruction/Reference

Librarian

University/College Library

Broward Community College

Davie, Florida

Adjunct English Instructor

1999-2003

Mentor, $2+2$ Distance Learning Undergraduate Studies Program in Information Studies Florida State University

Tallahassee, Florida

2000-2001

Reference Librarian/Distance Education Specialist

Founders Library

Howard University

Washington, D.C. 
2001-2004

2003-2004

2004-present
LibQUAL $+{ }^{\mathrm{TM}}$ Program Specialist

Statistics and Measurement Program

Association of Research Libraries

Washington, D.C.

Project Consultant

Historically Black Colleges and Universities (HBCU) Library Alliance Planning Grant

HBCU Library Alliance

Atlanta, Georgia

City University of New York

Chief Librarian, Medgar Evers College

Brooklyn, New York

Chief Librarian, Graduate School of

Journalism

New York, New York

\section{PUBLICATIONS}

Heath, F., Kyrillidou, M. \& Askew, C. (Eds.). (2004). From data to action: Libraries act on their LibQUAL $+{ }^{\mathrm{TM}}$ findings. West Hazelton, PA: Haworth Press. 